\title{
Validation of TRMM 3B42V7 Rainfall Product under Complex Topographic and Climatic Conditions over Hexi Region in the Northwest Arid Region of China
}

\author{
Xiuna Wang ${ }^{1,2}$, Yongjian Ding ${ }^{1,2,3, *}$, Chuancheng Zhao ${ }^{1,4}$ and Jian Wang ${ }^{5}$ \\ 1 Key Laboratory of Ecohydrology of Inland River Basin, Northwest Institute of Eco-Environment \\ and Resources, Chinese Academy of Sciences, Lanzhou 730000, China; wangxiuna@lzb.ac.cn (X.W.); \\ zhao_chch1978@163.com (C.Z.) \\ 2 College of Resources and Environment, University of Chinese Academy of Sciences, Beijing 100049, China \\ 3 State Key Laboratory of Cryospheric Sciences, Northwest Institute of Eco-Environment and Resources, \\ Chinese Academy of Sciences, Lanzhou 730000, China \\ 4 Department of Geography and Environmental Engineering, Lanzhou City University, Lanzhou 730000, China \\ 5 School of Urban and Planning, Yancheng Teachers University, Yancheng 224002, China; \\ wjshuigong@lzb.ac.cn \\ * Correspondence: dyj@lzb.ac.cn; Tel.: +86-931-496-7132
}

Received: 29 May 2018; Accepted: 27 July 2018; Published: 30 July 2018

\begin{abstract}
Continuous and accurate spatiotemporal precipitation data plays an important role in regional climate and hydrology research, particularly in the arid inland regions where rain gauges are sparse and unevenly distributed. The main objective of this study is to evaluate and bias-correct the Tropical Rainfall Measuring Mission (TRMM) 3B42V7 rainfall product under complex topographic and climatic conditions over the Hexi region in the northwest arid region of China with the reference of rain gauge observation data during 2009-2015. A series of statistical indicators were adopted to quantitatively evaluate the error of 3B42V7 and its ability in detecting precipitation events. Overall, the 3B42V7 overestimates the precipitation with Bias of $11.16 \%$, and its performance generally becomes better with the increasing of time scale. The agreements between the rain gauge data and $3 \mathrm{~B} 42 \mathrm{~V} 7$ are very low in cold season, and moderate in warm season. The 3B42V7 shows better correlation with rain gauges located in the southern mountainous and central oasis areas than in the northern extreme arid regions, and is more likely to underestimate the precipitation in high-altitude mountainous areas and overestimate the precipitation in low-elevation regions. The distribution of the error on the daily scale is more related to the elevation and rainfall than in monthly and annual scale. The 3B42V7 significantly overestimates the precipitation events, and the overestimation mainly focuses on tiny amounts of rainfall $(0-1 \mathrm{~mm} / \mathrm{d})$, which is also the range of false alarm concentration. Bias correction for 3B42V7 was carried out based on the deviation of the average monthly precipitation data during 2009-2015. The bias-corrected 3B42V7 was significantly improved compared with the original product. Results suggest that regional assessment and bias correction of 3B42V7 rainfall product are of vital importance and will provide substantive reference for regional hydrological studies.
\end{abstract}

Keywords: TRMM 3B42V7; accuracy evaluation; bias correction; complex terrain; climatic transitional zone; northwest arid region 


\section{Introduction}

At present, global climate change and frequent human activities have caused a profound impact on the hydrological cycle [1-4]. These changes are particularly pronounced in the arid region where the water circulation and the stability of ecosystems are more severe due to water shortages [5,6]. Continuous, accurate and reliable precipitation observation is key important input variable for climatic and hydrologic research $[7,8]$. However, meteorological stations are very sparse and unevenly distributed in most arid and semi-arid regions for the adverse natural conditions $[9,10]$, and the available precipitation data cannot meet the needs of the climate and hydrological research. Moreover, the existing meteorological stations are mostly located in plains or valleys, from which the observed precipitation data cannot effectively reflect the precipitation characteristics of the high lands, where the cold alpine areas are the runoff-forming regions [8]. These limitations make it difficult to recognize and understand the water cycle in the arid inland regions.

Over the past decade, several projects on monitoring precipitation have been carried out at global scale to improve the spatial and temporal estimation of precipitation. Satellite remote sensing precipitation products are particularly valuable in providing spatial-temporal continuous rainfall data, especially in areas where in situ measurements are sparse (leading to greater uncertainty in spatial interpolation products) or absent, like the arid region of northwest China [11-14]. Tropical Rainfall Measuring Mission (TRMM) is one of the most important precipitation projects in hydrological research. In the past few years, numerous studies have been carried out to validate the TRMM precipitation product in different regions [15-20]. Tong et al. evaluated four widely used global high-resolution satellite precipitation products against gauge streamflow observations over the Tibetan Plateau [21]. The good performance of 3B42V7 rainfall product was reported in simulating both monthly and daily runoff against CMORPH, PERSIANN, and TRMM 3B42RT [21]. Li et al. demonstrated that TRMM satellite was inclined to underestimate the monthly rainfall in Xinjiang catchment, Poyang lake basin [22]. Yang et al. evaluated the TRMM 3B42V7 rainfall product using gauge precipitation observations and then investigated its application in supporting reservoir operation and water resources management, considered that the $3 \mathrm{~B} 42 \mathrm{~V} 7$ can capture well the spatial and temporal characteristics of precipitation and perform well in water allocation decision-making over the Hanjiang basin in China [23]. Different studies show that the applicability and accuracy of the satellite rainfall products in different regions are significantly differ for diverse inversion algorithm and underlying surface $[19,24-26]$.

Satellite rainfall products are affected typically by systematic and random error [27]. The uncertainty of data accuracy and its insufficient latency and spatial/temporal resolution all limit the application of satellite rainfall products in hydrological research [28]. Recent studies have shown that even in poorly measured areas, hydrological simulations using satellite rainfall products are comparable or inferior in performance to simulations using even a small amount of ground rain gauges [29,30]. Thus, bias correction is an important prerequisite for applying these spaceborne rainfall data to hydrological models. The bias correction method can vary from simple linear correction [31] to a more complex histogram matching, which can correct multiple moments of the variable distribution at one time [32]. Additionally, bias correction work has proven to improve the original satellite rainfall product.

The northwest Arid Region of China is one of the regions most sensitive to global climate warming [33,34]. Complex topographic and climatic conditions as well as the sparse distribution of meteorological stations here all make it difficult to observe the precipitation, whereas the sensitive eco-hydrological environment within the region makes the regional hydrology, climate and ecological research extremely important [35-38]. With such a background, continuous and accurate precipitation products are crucial. Furthermore, the precision of different satellite precipitation products and reanalyzed precipitation datasets also have an important dependence on regional terrain conditions, climate conditions and even the density of weather stations $[39,40]$. Accurately assessing the error characteristics of different rainfall products in the arid region has a crucial role for regional climate and hydrological research as well as the precipitation products' improvement. However, due to the limited 
ground-based observations, the assessment of satellite precipitation products in the northwestern arid region is relatively rare and faces enormous challenges.

Water resources in the Hexi region are mainly distributed in a number of relatively independent inland river basins, of which the cold alpine areas are the runoff-forming regions, while the piedmont plains or basins are the runoff loss regions. Such topographic features and spatial distribution characteristic of runoff result in the unique hydrological and water resources systems in the northwest arid region of China. Water resources in arid inland river basins of the Hexi region are not only valuable resources, but also an important environmental factor due to the low precipitation and dry climate. Accurate spatial and temporal precipitation data is of great significance to climate and hydrology research in the Hexi region. However, the complex terrain caused a complexity of the precipitation distribution and more difficulties to observe precipitation in the area. Although many evaluation studies have been launched, the comprehensive data assessing work for the Hexi region is still rare. How accurately the satellite rainfall products reflect the precipitation in mountainous, oasis and deserts in the inland arid region of northwestern China remains unknown. Thus, we selected the TRMM 3B42V7 rainfall product and quantitatively evaluated its error characteristic and detection capability based on existing meteorological stations and in situ observed precipitation data from 2009-2015. Additionally, the causes of different error indicators were briefly analyzed. Results of the paper will provide detailed data support and references for the climate and hydrology research as well as rainfall data accuracy corrections for the Hexi region.

\section{Materials and Methods}

\subsection{Study Area}

The Hexi region is located in the northeastern edge of the Qinghai-Tibet Plateau descending zone, where is the transitional zone between the Asian summer monsoon and westerlies [41], within a latitude of $36.8-43.0^{\circ} \mathrm{N}$ and longitude of $92.9-104.5^{\circ} \mathrm{E}$ (Figure 1), which have an area of $31.72 \times 10^{4} \mathrm{~km}^{2}$. There are three inland river basins in the study area: the Shiyang River basin, the Hei River basin and the Shule River basin. The region also includes two deserts: the Badain Jaran desert and the Tengger desert. The Hexi region is dominated by an arid continental climate, with an annual mean air temperature of $5-9{ }^{\circ} \mathrm{C}$. The annual mean precipitation decreases from more than $500 \mathrm{~mm}$ in the southern mountains to less than $50 \mathrm{~mm}$ in the northern desert with an average evaporation of over $2000 \mathrm{~mm}$ per year [42,43]. The precipitation also shows an obvious seasonal distribution characteristic, more than $75 \%$ of the annual rainfall occurred during the period July to August [44]. Rivers of the Hexi region originating from the Qilian Mountains are ephemeral, flowing from south to north through the oasis and disappearing into the deserts. Precipitation and melting water from high-altitude mountains are important water supply to the rivers [6]. The density of meteorological stations in the study area is relatively low, approximately $15,858.71 \mathrm{~km}^{2} /$ rain gauge, which is far below the national average. What is more, affected by the regional physical and geographical conditions, the meteorological stations here are extremely unevenly distributed, and are mostly located in the oasis zone with a mean elevation of 2000-3000 m. The scarcity of meteorological stations in the high mountainous and the desert regions has hampered hydrology and water resources research in the Hexi region. 


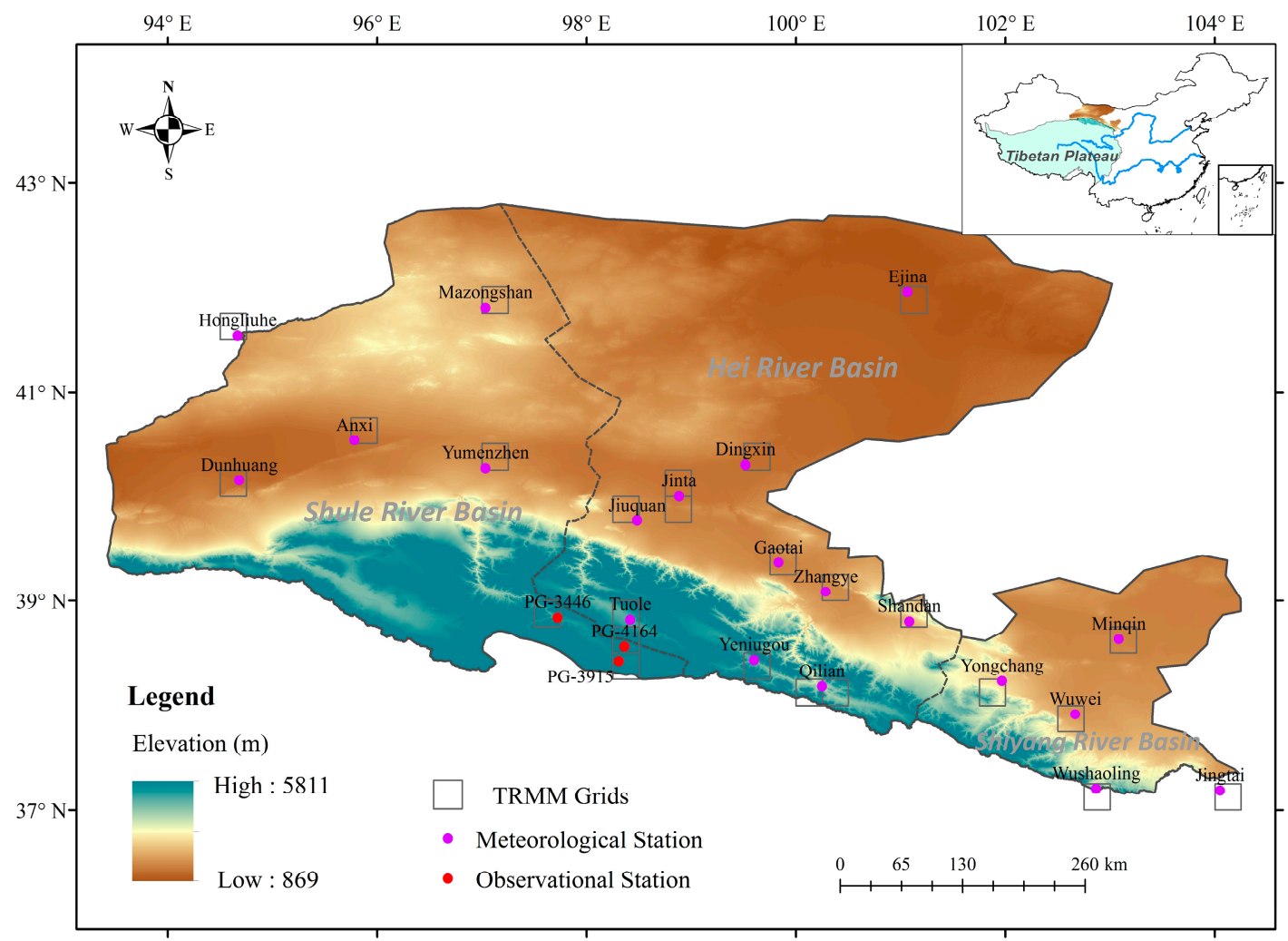

Figure 1. Study location of the HEXI Region with the spatial distribution of stations and TRMM 3B42V7 grid boxes in it.

\subsection{Data}

\subsubsection{TRMM Satellite Precipitation Data}

TRMM is a joint mission between the National Aeronautics and Space Administration (NASA) and the Japan Aerospace Exploration Agency (JAXA), and aims to measure the intensity and area coverage of rainfall around the tropical and semi-tropical area where two thirds of the world's rainfall happens [45,46]. TRMM 3B42V7 precipitation product can provide relatively high-precision precipitation data with temporal resolution of $3 \mathrm{~h}$ and spatial resolution of $0.25^{\circ} \times 0.25^{\circ}$ between latitude $50^{\circ} \mathrm{N}$ and latitude $50^{\circ} \mathrm{S}$, which were used in this study. The daily meteorological precipitation data used in the study is the total precipitation between 20:00 of the previous day and 20:00 of the current day in UTC 8. For the sake of uniting time, we converted the 3B42V7 rainfall data from UTC 0 into UTC 8 of the Hexi region, corresponding to the precipitation of 12:00 of the previous day to 12:00 of the current day [19]. The 3B42V7 rain rate is a 3-hourly average centered at the middle of each 3-h period (i.e., 0Z, 3Z, 6Z, 9Z, 12Z, 15Z, 18Z, and 21Z). To convert these rainfall rates to total daily rainfall, first multiply each 3-hourly rainfall rate by $3 \mathrm{~h}$, to get the total rainfall for each 3-h period. In order to compare the product with observed precipitation data, 3-h 3B42V7 data were accumulated to derive the daily, monthly and annual precipitation from 2009-2015.

\subsubsection{Meteorological Stations Based Precipitation Data}

The daily precipitation datasets from 23 meteorological stations were used to evaluate the TRMM 3B42V7 precipitation product in this study. The data of the 20 meteorological stations were downloaded from the China National Meteorological Information Center (http:/ / data.cma.cn/). The daily data downloaded were also used to calculate the monthly, seasonal and the annual total precipitation in the HEXI Region from 2009-2015. The data for the three additional stations were obtained from the Shule River Field Observational Stations, Chinese Academy of Science. The observed precipitation 
data (PG-3446, PG-3915 and PG-4164) were measured by Geonor T-200B weighing gauge (sensitivity $0.1 \mathrm{~mm}$ ), which were set in July 2008 with the time resolution of $10 \mathrm{~min}$. In order to reduce the rainfall loss caused by wind and evaporation, a windproof ring was installed, and antifreeze and oil were also added to the tank of the Geonor T-200B weighing gauge (Geonor, Inc., Oslo, Norway). The evaluation of the TRMM 3B42V7 rainfall product was carried out for daily, monthly, seasonal and annual aggregate periods. Table 1 lists the rain gauges that were used in this study.

Table 1. Details of geographical coordinates and precipitation for rain gauges in the Hexi region.

\begin{tabular}{ccccc}
\hline Station & Longitude $\left({ }^{\circ} \mathbf{E}\right)$ & Latitude $\left({ }^{\circ} \mathbf{N}\right)$ & Altitude $(\mathbf{m})$ & Annual Precipitation $(\mathbf{m m})$ \\
\hline Ejina & 101.07 & 41.95 & 940.5 & 31.63 \\
Hongliuhe & 94.67 & 41.53 & 1573.8 & 50.39 \\
Mazongshan & 97.03 & 41.80 & 1770.4 & 68.06 \\
Dunhuang & 94.68 & 40.15 & 1139 & 43.10 \\
Anxi & 95.77 & 40.53 & 1170.9 & 80.63 \\
Yumenzhen & 97.03 & 40.27 & 1526 & 63.37 \\
Dingxin & 99.52 & 40.30 & 1177.4 & 69.74 \\
Jinta & 98.90 & 40.00 & 1270.5 & 99.54 \\
Jiuquan & 98.48 & 39.77 & 1477.2 & 115.17 \\
Gaotai & 99.83 & 39.37 & 1332.2 & 355.90 \\
Tuole & 98.42 & 38.80 & 3367 & 478.59 \\
Yeniugou & 99.58 & 38.42 & 3320 & 128.07 \\
Zhangye & 100.43 & 38.93 & 1482.7 & 440.83 \\
Qilian & 100.25 & 38.18 & 2787.4 & 217.40 \\
Shandan & 101.08 & 38.80 & 1764.6 & 220.30 \\
Yongchang & 101.97 & 38.23 & 1976.9 & 165.87 \\
Wuwei & 102.67 & 37.92 & 1531.5 & 117.51 \\
Minqin & 103.08 & 38.63 & 1367.5 & 432.07 \\
Wushaoling & 102.87 & 37.20 & 3045.1 & 180.37 \\
Jingtai & 104.05 & 37.18 & 1630.9 & 224.91 \\
PG-3446 & 97.72 & 38.84 & 3446 & 367.01 \\
PG-3915 & 98.31 & 38.42 & 3915 & 377.52 \\
PG-4164 & 98.36 & 38.56 & 4164 & \\
\hline
\end{tabular}

\subsection{Methods}

\subsubsection{Assessment Methods}

In this study, six widely used statistical approaches were adopted to evaluate the TRMM 3B42V7 rainfall product against the rain gauge data. Correlation Coefficient (CC) measures the goodness of fit and linear association between satellite products and rain gauge data [23]. Root Mean Square Error (RMSE) is used to measure the average error magnitude, and is very sensitive to the outliers. Mean Error (ME) refers to the average of all the errors between satellite precipitation and rain gauge observations. Mean Absolute Error (MAE) is the mean of absolute error, which can better reflect the actual situation of the satellite products' error. Relative Bias (Bias) describes the systematic deviation between satellite precipitation and rain gauge data, whereas Relative Absolute Bias (ABias) shows the absolute bias of satellite products $[17,18]$. The mathematical representations for CC, RMSE, ME, MAE, Bias and ABias are given below:

$$
\begin{gathered}
\mathrm{CC}=\frac{\sum_{i=1}^{n}\left(P_{g i}-\overline{P_{g}}\right)\left(P_{s i}-\overline{P_{s}}\right)}{\sqrt{\sum_{i=1}^{n}\left(P_{g i}-\overline{P_{g}}\right)^{2}} \sqrt{\sum_{i=1}^{n}\left(P_{s i}-\overline{P_{s}}\right)^{2}}} \\
\text { RMSE }=\sqrt{\frac{1}{n} \sum_{i=1}^{n}\left(P_{s i}-P_{g i}\right)^{2}}
\end{gathered}
$$




$$
\begin{gathered}
\mathrm{ME}=\frac{1}{n} \sum_{i=1}^{n}\left(P_{s i}-P_{g i}\right) \\
\mathrm{MAE}=\frac{1}{n} \sum_{i=1}^{n}\left|P_{s i}-P_{g i}\right| \\
\mathrm{Bias}=\frac{\sum_{i=1}^{n}\left(P_{s i}-P_{g i}\right)}{\sum_{i=1}^{n} P_{g i}} \times 100 \\
\text { ABias }=\frac{\sum_{i=1}^{n}\left|P_{s i}-P_{g i}\right|}{\sum_{i=1}^{n} P_{g i}} \times 100
\end{gathered}
$$

where $P_{g i}, P_{s i}$ are the values of the rain gauge observations and the satellite precipitation estimates in corresponding stations $(\mathrm{mm}) ; \overline{P_{g}}, \overline{P_{s}}$ are the mean values of the rain gauge data and the satellite precipitation estimates $(\mathrm{mm}) ; i$ is the index of the station or satellite precipitation number and $n$ is the total number of stations or satellite precipitation data.

In order to evaluate the ability of TRMM 3B42V7 to detect rain/no rain events, four categorical statistical indices were also adopted in this study: Probability of Detection (POD), False alarm Rate (FAR), Frequency Bias Index (FBI) and Critical Success Index (CSI) $[18,19,47]$. POD, also known as the hit rate, denotes the ratio of rain events that were correctly detected to the total observed events by rain gauge. FAR gives the fraction of rain events falsely alarmed to the total detected events by satellite. FBI is the ratio of the rain events detected by satellite to the observed ones by rain gauge. Critical success index (CSI) measures the ratio of rain events correctly detected by satellite to the total number of all observed and detected rain events. The mathematical representations of these indices are given below:

$$
\begin{gathered}
\mathrm{POD}=\frac{H}{H+M} \\
\mathrm{FAR}=\frac{F}{H+F} \\
\mathrm{FBI}=\frac{H+F}{H+M} \\
\mathrm{CSI}=\frac{H}{H+F+M}
\end{gathered}
$$

where $H$ is the number of hit (i.e., precipitation event was detected to occur and observed to occur), $M$ is the number of miss (i.e., precipitation event was not detected to occur but observed to occur), $F$ is the number of false alarm (i.e., precipitation event was detected to occur but not observed to occur), and $N$ is the number of correct negative (i.e., precipitation event was not detected to occur and not observed to occur). The perfect scores of POD, FAR, FBI and CSI are 1, 0, 1 and 1, respectively.

\subsubsection{BIAS Correction Methods}

For TRMM 3B42V7 rainfall product, several different time scales (hourly, daily, monthly, etc.) have been considered for bias correction. The monthly precipitation estimate, due to its relatively long series and high correlation with ground observation, is widely discussed in bias correction studies [48-51]. In this study, we adopted the bias correction method of Arias-Hidalgo et al. [48] to improve the 3B42V7 rainfall product in the Hexi region. This method assumes that the bias of 3B42V7 at a specific grid is similar to those nearest grid with a station inside it. It also assumes that if the 3B42V7 at grids with stations overestimate or underestimate the precipitation by a certain percentage, the 3B42V7 values of nearby grids contain the similar biases, and these biases can be removed from the original 3B42V7 estimates.

First, the accumulated monthly precipitation measured at each station was compared with their 3B42V7 estimates during the study period (2009-2015). Equation (11) expresses a relationship between 
station and its corresponding original 3B42V7 monthly estimates, at a certain station $i$. Then the corrected 3B42V7 monthly precipitation at the location $i$ can be calculated as follows:

$$
\begin{gathered}
K_{i}=\frac{G P_{i}}{T R M M_{i}} \\
T_{R M M_{c o r r, i, m}}=K_{i} \times T R M M_{i, m}
\end{gathered}
$$

where $K_{i}$ is the bias corrector factor at the station $i ; G P_{i}$ is the accumulated monthly rainfall from ground observations at station $i ; T R M M_{i}$ is the accumulated monthly rainfall of original $3 \mathrm{~B} 42 \mathrm{~V} 7$, at the location of station $i$; TRMM $M_{i, m}$ is the original 3B42V7 monthly rainfall (mm/month), at the location of station $i$ during the month $m$; TRM $M_{\text {corr }, i, m}$ is the bias-corrected monthly $3 \mathrm{~B} 42 \mathrm{~V} 7$ precipitation value at station $i$ (mm/month) during the month $m$.

In order to obtain the bias-corrected data at daily scale, the bias-corrected 3B42V7 monthly precipitation values were disaggregated into daily time series ones for each grid. To achieve this, temporal disaggregation coefficients $\left(f_{i}\right)$ were first derived from the station daily time series, and then applied back to the bias-corrected 3B42V7 monthly values to calculate the daily series estimates. The bias-corrected daily precipitation was calculated as follows:

$$
\begin{gathered}
f_{i, d, m}=\frac{P_{i, d, m}}{T P_{i, m}} \\
T R M M_{c o r r, i, d}=f_{i, d, m} \times T R M M_{c o r r ~}, i, m
\end{gathered}
$$

where $f_{i, d, m}$ is the temporal disaggregation coefficient at the station $i$, for the day $d$ of month $m ; P_{i, d, m}$ is the total rainfall at the station $i$ on the day $d$ of month $m\left(\mathrm{~mm} /\right.$ day); $T P_{i, m}$ is the accumulated rainfall at the station $i$ during month $m$ (mm/month); TRM $M_{\text {corr }, i, d}$ is the disaggregated, bias-corrected daily 3B42V7 precipitation value at station $i(\mathrm{~mm} /$ day) for month $m$.

\section{Results and Discussion}

\subsection{Assessment Results}

\subsubsection{Overall Assessment}

In this section, comparative analyses of precipitation at different time scales are discussed. Figure 2 shows the rainfall scatter plots of 3B42V7 against meteorological stations over the Hexi region at multi-time scales from 2009-2015. In general, the 3B42V7 rainfall product can reflect the distribution of precipitation in the study area. On the daily time scale (Figure 2a), a correlation of 0.53 is shown between 3B42V7 rainfall product and the meteorological stations data. As for numerical differences, a slight overestimation is shown by 3B42V7 rainfall product with the ME of $0.06 \mathrm{~mm}$. In addition, the average error magnitude of 3B42V7 measured by MAE and RMSE is 0.64 and $2.21 \mathrm{~mm}$ respectively, indicating a slight difference between 3B42V7 rainfall product and the meteorological stations data. From Figure $2 b, c$, the CC values for monthly and annual precipitation data are $0.89,0.91$, respectively, which indicates an obvious linear correlation and consistency between 3B42V7 and rain gauge precipitation data. In terms of bias, the Relative Bias (Bias) and Relative Absolute Bias (ABias) between the two datasets were calculated respectively. As shown in Table 2, the same Bias $(11.16 \%)$ is got on the daily, monthly, and annual time scales, but the ABias tends to decrease as the time scale increases $(121.99 \%, 43.80 \%, 25.87 \%$ respectively). With the increase of time scale, the values of ME, MAE and RMSE of 3B42V7 increase and the ABias decrease, indicate an increase in deviation amount and decrease in deviation ratio. On the whole, the 3B42V7 rainfall product can capture the variations of precipitation in the Hexi region, but its overestimation compared with ground observations is not negligible in the process of data use. 

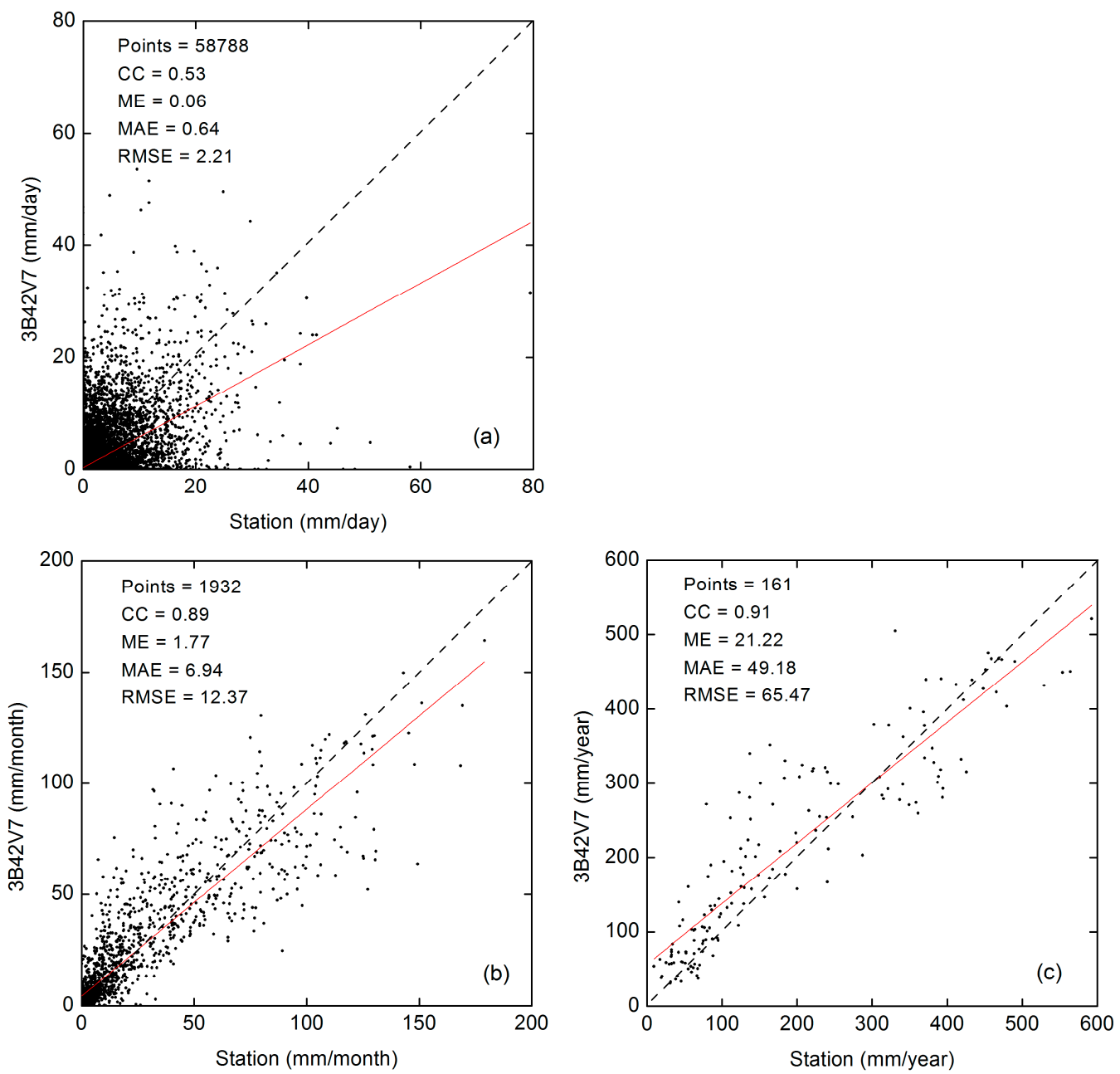

Figure 2. Comparison of precipitation measured by meteorological stations and TRMM 3B42V7 at different time scales: (a) daily, (b) monthly, (c) annual. The dash line is the 1:1 line, and the red solid one represents the linear regression fitting line.

Compared with other evaluation studies in China, the accuracy of 3B42V7 rainfall product in the Hexi region is significantly lower than that in the southeastern region of China [18,23,52], but slightly better than that of the Tibetan Plateau [17,21]. The main reason for this difference is the different geographical location, underlying surface and climate conditions in different research areas, which will significantly affect the detection capability of remote sensing satellites [53-55]. Furthermore, the 3B42V7 rainfall product incorporates various satellite datasets and Global Precipitation Climatology Center (GPCC) data with improved climatology and anomaly analysis [19,56,57], and uses many gauging stations in bias correction algorithm $[58,59]$. Therefore, the ground observation density will affect the accuracy of the product to a certain extent. About the bias correction of the TRMM, a very interesting difference was found between our research and the study by Cai et al. [19] in the HunTai Basin, where a larger bias and lower CC values was represented. The HunTai Basin (situated between $40.5-42.5^{\circ} \mathrm{N}$ ) in northeast of China and the Hexi region (situated between 36.8-43. $0^{\circ} \mathrm{N}$ ) in northwestern China are both located in the middle latitudes, which are beyond the inclined TRMM satellite orbital latitude band $\left(36^{\circ} \mathrm{NS}\right)$, with a complex terrain. However, its density of the meteorological stations is far greater than that of the Hexi region $\left(226.46 \mathrm{~km}^{2} /\right.$ rain gauge vs. $15,858.71 \mathrm{~km}^{2} /$ rain gauge) [19]. In the context of such high density of meteorological stations, the reason for the lower accuracy of 3B42V7 rainfall product in the HunTai Basin is mainly related to its distinctive terrain and relatively high latitude location. 
Overall, the accuracy of TRMM 3B42V7 rainfall product is significantly affected by the elevation, climatic conditions, underlying surface and latitude of the study area. The accuracy of 3B42V7 in the Hexi region is relatively low; its error and detection capabilities at different time scales and spaces will be elaborated in the following sections.

Table 2. Statistics for 3B42V7 at different time scales.

\begin{tabular}{cccc}
\hline Statistical Indicators & Daily & Monthly & Annual \\
\hline Mean (Station, 3B42V7) & $(0.52,0.58)$ & $(15.84,17.61)$ & $(190.12,211.34)$ \\
CC & 0.53 & 0.89 & 0.91 \\
ME & 0.06 & 1.77 & 21.22 \\
MAE & 0.64 & 6.94 & 49.18 \\
RMSE & 2.21 & 12.37 & 65.47 \\
Bias & 11.16 & 11.16 & 11.16 \\
ABias & 121.99 & 43.80 & 25.87 \\
\hline
\end{tabular}

\subsubsection{Seasonal Assessment}

Precipitation in the Hexi region has an obvious seasonal distribution characteristic. By calculating the rainfall at the 23 stations from 2009 to 2015, the proportion of precipitation in different seasons was obtained: $2.67 \%$ in spring (January-March), 34.78\% in summer (April-June), 56.59\% in autumn (July-September), and $5.96 \%$ in winter (October-December). According to Equations (1)-(6), the statistical indicators of seasonal rainfall between rain gauge data and 3B42V7 in different seasons were calculated in Figure 3. Results show that the 3B42V7 generally overestimates the rainfall in all seasons, and the detection ability varies greatly in different seasons. The CC values are much higher in autumn (0.91) and summer (0.84) than in winter (0.57) and spring (0.51). Other indicators were also calculated respectively in Table 3 . The Bias is lowest in fall, at $6.01 \%$, followed by summer $(11.32 \%)$, and the winter and spring were $36.08 \%$ and $62.79 \%$ respectively. Similar results are shown in ABias scores, lowest in autumn (26.86\%), followed by summer (35.22\%), winter (63.67\%) and spring (91.77\%). The respective scores of other three indicators are as follows: RMSE (Spring: 5.73 mm; Summer: 31.12 mm; Autumn: 38.56 mm; Winter: 9.77 mm); ME (Spring: 3.19 mm; Summer: $7.48 \mathrm{~mm}$; Autumn: $6.46 \mathrm{~mm}$; Winter: $4.09 \mathrm{~mm}$ ); MAE (Spring: $4.66 \mathrm{~mm}$; Summer: $23.29 \mathrm{~mm}$; Autumn: $28.90 \mathrm{~mm}$; Winter: $7.21 \mathrm{~mm}$ ). Combining the results of the six indicators, the 3B42V7 rainfall product is considered to have better detection capabilities in summer and autumn.

In general, the 3B42V7 rainfall product performs better during warm season (summer and autumn) than in cold season (spring and winter). This is consistent with the study of Chen et al. [60] and Zhao et al. [61] that evaluated TRMM 3B42V7 rainfall product over China. The relatively high latitude location of the Hexi region and its significant seasonal distribution of precipitation are the main factors for this seasonal difference. As we all know, The TRMM was originally launched to measure the intensity and area coverage of rainfall around the tropical and semi-tropical areas, as the latitude increases, the detection capability gradually decreases. In addition, the TRMM sensors have better detection capability on the heavy precipitation cloud system $[14,62]$, while over $90 \%$ of the precipitation in the Hexi region is concentrated in the warm season, and the heavy precipitation events are all concentrated in this period. In contrast, the poor performance of TRMM 3B42V7 during the cold season can be attributed to the poor detection capability of the light precipitation (less than $3 \mathrm{~mm} /$ day) [63]. Therefore, when 3B42V7 rainfall product is applied to climate and hydrological researches, further data corrections are required. Special attention should be paid to the error distribution characteristics of different seasons, and the improvement in cold season must be strengthened. 

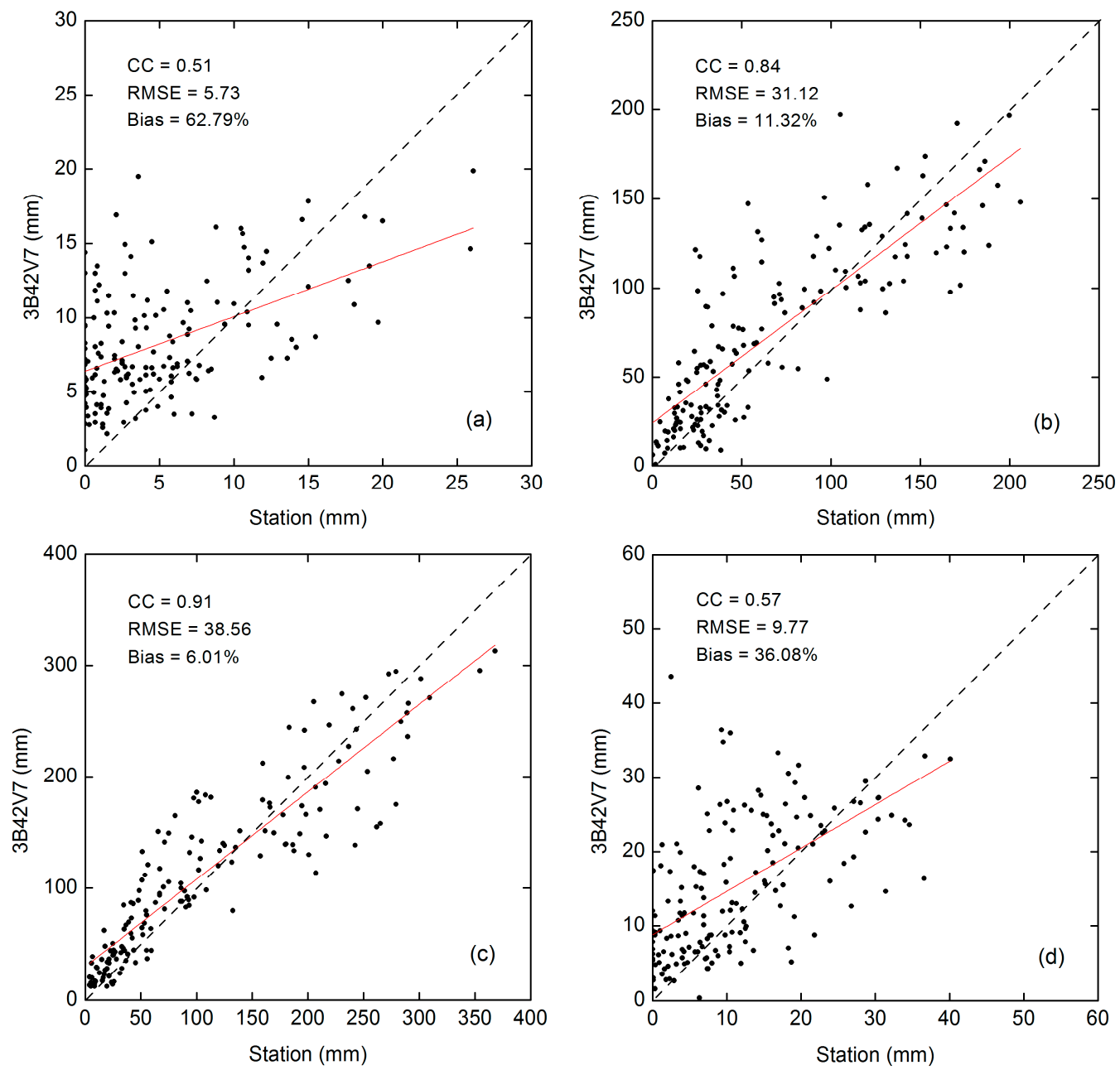

Figure 3. Comparison of seasonal precipitation measured by meteorological stations and TRMM 3B42V7: (a) Spring, (b) Summer, (c) Autumn, (d) Winter. The legend is same to Figure 2.

Table 3. Statistics for 3B42V7 in different seasons.

\begin{tabular}{ccccc}
\hline Statistical Indicators & Spring & Summer & Autumn & Winter \\
\hline Mean (Station, 3B42V7) & $(5.07,8.26)$ & $(66.13,73.61)$ & $(107.59,114.06)$ & $(11.33,15.41)$ \\
CC & 0.51 & 0.84 & 0.91 & 0.57 \\
ME & 3.19 & 7.48 & 6.46 & 4.09 \\
MAE & 4.66 & 23.29 & 28.90 & 7.21 \\
RMSE & 5.73 & 31.12 & 38.56 & 9.77 \\
Bias & 62.79 & 11.32 & 6.01 & 36.08 \\
ABias & 91.77 & 35.22 & 26.86 & 63.67 \\
\hline
\end{tabular}

\subsubsection{Spatial Distribution of the Error Statistics at Different Time Scales}

The spatial distribution of precipitation in the Hexi region not only shows a trend of increasing with altitude, but also presents a significant increasing trend along with the increase of longitude, characterized by the rainfall's gradually increase from north to south, west to east. In order to analyze the relationship between the error indices of 3B42V7 rainfall product and different topographic features, we calculated the six evaluation metrics (CC, RMSE, ME, MAE, Bias and ABias) for different stations and plotted the spatial distribution of different parameters at daily, monthly and annual, respectively.

On the daily scale, there is a moderate correlation (Figure 4a) between 3B42V7 and meteorological station data, and better correlation is found as the altitude and rainfall increasing. The CC values of 
11 sites in 23 sites are lower than 0.5 , while the remaining 12 sites are higher than 0.5 . The elevations of the 11 stations with correlations less than 0.5 are all less than $1700 \mathrm{~m}$, except for the sites PG-3446 (0.49) and PG-3915 (0.34). For stations with corresponding CC values higher than 0.5, the site altitude is higher than $1700 \mathrm{~m}$, except for the Gaotai, Jiuquan, Zhangye and Yumenzhen stations. Similar results were reported in the study of Cai et al. [19] and Xue et al. [64], where the mountainous areas show better correlation between 3B42V7 and the rain gauge data. However, the finding is inconsistent with the study by Tan et al. [14] in the Kelantan River Basin, Malaysia, where lower CC values are found over the mountainous regions in the southwestern part of the basin. The reason for this difference is related to the different geographical location and magnitude of precipitation in different study area. Generally, the 3B42V7 shows a good correlation with stations located in the southern mountainous and central oasis areas, whereas, weak correlation is found in the northern extreme arid region. Altitude and rainfall are important factors for this distribution characteristic.

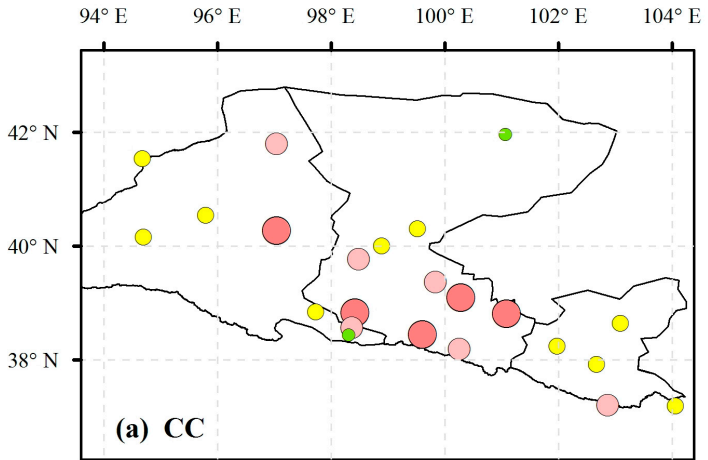

(a) $\mathrm{CC}$

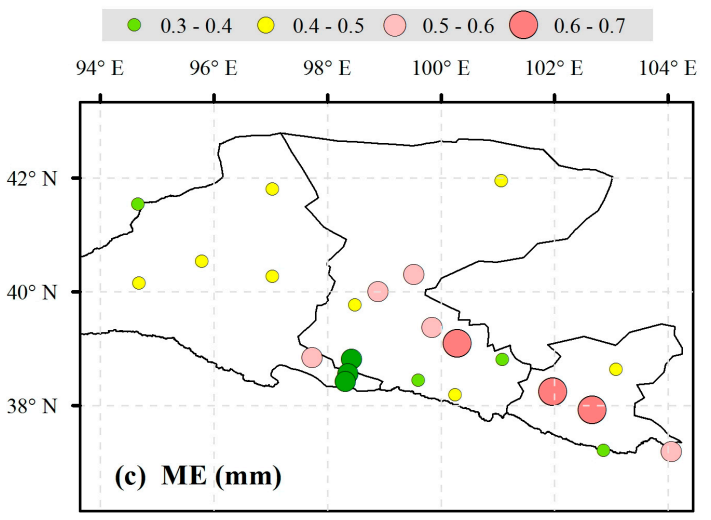

$-0.2--0.1 \bigcirc-0.1-0 \bigcirc 0-0.1 \bigcirc 0.1-0.2 \bigcirc 0.2-0.5$

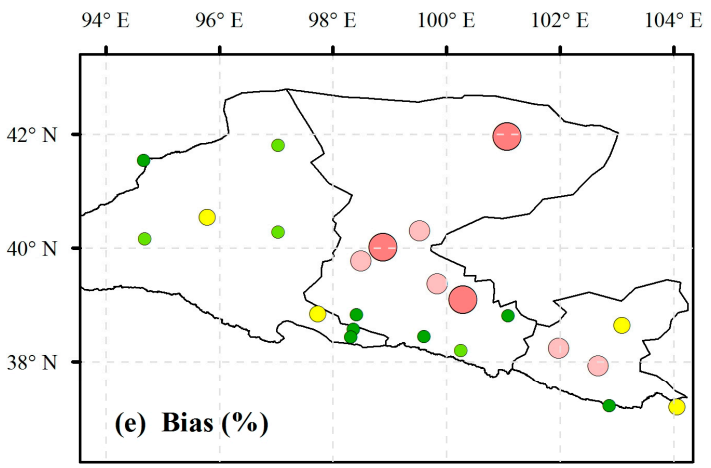

$-15-0 \bigcirc 0-15 \bigcirc 15-30 \bigcirc 30-80 \bigcirc 80-120$

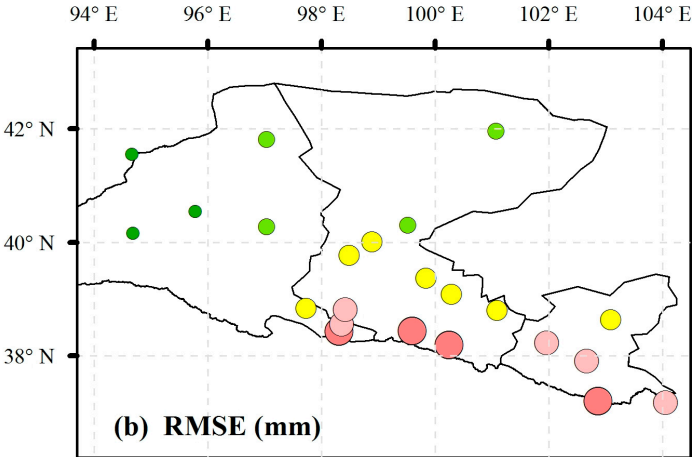

$0.8-1.0 \bigcirc 1.0-1.5 \bigcirc 1.5-2.5 \bigcirc 2.5-3.0 \bigcirc 3.0-3.5$

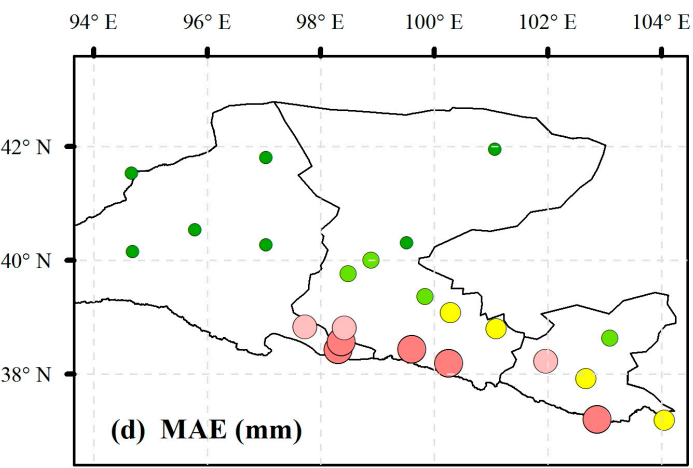

$0.1-0.3 \bigcirc 0.3-0.5 \bigcirc 0.5-0.8 \bigcirc 0.8-1 \bigcirc 1-1.3$

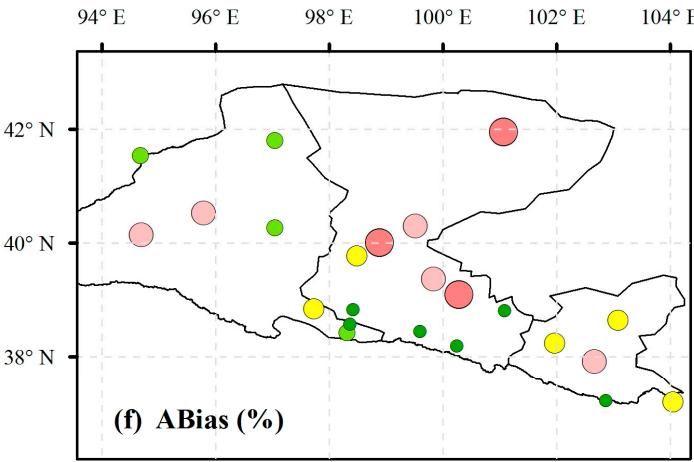

- $96-110 \bigcirc 110-130 \bigcirc 130-150 \bigcirc 150-170 \bigcirc 170-225$

Figure 4. Spatial distribution of six continuous statistical indices based on daily precipitation from 2009-2015: (a) CC, (b) RMSE, (c) ME, (d) MAE, (e) Bias, and (f) ABias. 
The error magnitude of 3B42V7 measured by RMSE (MAE) ranges from 0.8 to $3.5 \mathrm{~mm}$ (0.1 to $1.3 \mathrm{~mm}$ ), and exhibits a significant decreasing trend from south to north, east to west (Figure $4 \mathrm{~b}, \mathrm{~d}$ ). Unlike the distribution of RMSE and MAE, the ME performance of different sites is more complex. As shown in Figure $4 \mathrm{c}$, the $\mathrm{ME}$ ranges from -0.2 to $0.5 \mathrm{~mm}$, and the negative values are mostly distributed at the sites above $3000 \mathrm{~m}$, which suggests that the 3B42V7 rainfall product is more likely to underestimate the precipitation in high-altitude mountainous areas and overestimate the precipitation in low-elevation areas.

As for bias, the Relative Bias (Bias) and Relative Absolute Bias (ABias) at the daily scale between the two datasets in different stations were calculated respectively. Figure $4 \mathrm{e}, \mathrm{f}$ both indicate that the 3B42V7 rainfall product has superior precipitation detection capabilities in high altitudes than in low altitudes. In Figure $4 \mathrm{e}$, the Bias ranges from $-15 \%$ to $120 \%$. The negative values are relatively small and are concentrated in high-altitude sites in the southern part of the study area. Whereas, most of the low altitude stations in the northern extreme arid area have positive values and are relatively high in magnitude. In Figure $4 \mathrm{f}$, the ABias ranges from $96 \%$ to $225 \%$, with lower values concentrated in the southern mountainous stations. As the altitude and rainfall gradually decrease, the ABias value increases from south to north, and the maximum value is located at the Ejina station, which is the northernmost station in the Hexi region.

In order to analyze the relations between evaluation metrics and elevation/rainfall, scatter plots of the six consecutive statistical indicators for each station against its elevation/average annual rainfall were shown in Figure 5. All the six evaluation metrics show similar trend for both elevation and average annual rainfall. With the increase of elevation/average annual rainfall, CC, RMSE and MAE increase, whereas, ME, Bias and ABias show a decrease trend. It is important to note that MAE, ABias and RMSE show a better linear relationship with altitude/average annual rainfall than CC, ME and Bias, of which the first three indicators all measure the absolute error magnitude, and the following three indices measure the relative error. This indicates that the absolute error distribution characteristics of 3B42V7 rainfall product have a significant correlation with altitude and rainfall. Furthermore, it is very interesting to find that the decrease trend of Bias with increasing elevation/rainfall (Figure 5i,j) is different from the study by $\mathrm{Xu}$ et al. [17] over southern Tibetan Plateau, where with the increase of rainfall, Bias of TRMM also increase. The reason for this difference may be attributed to the discrepancy in precipitation amount. The Hexi region is located in the northeastern edge of the Qinghai-Tibet Plateau descending zone, with an average precipitation of just $0.52 \mathrm{~mm} / \mathrm{d}$, while the average precipitation over southern Tibetan Plateau is $2.42 \mathrm{~mm} / \mathrm{d}$ [17], about five times of the former.
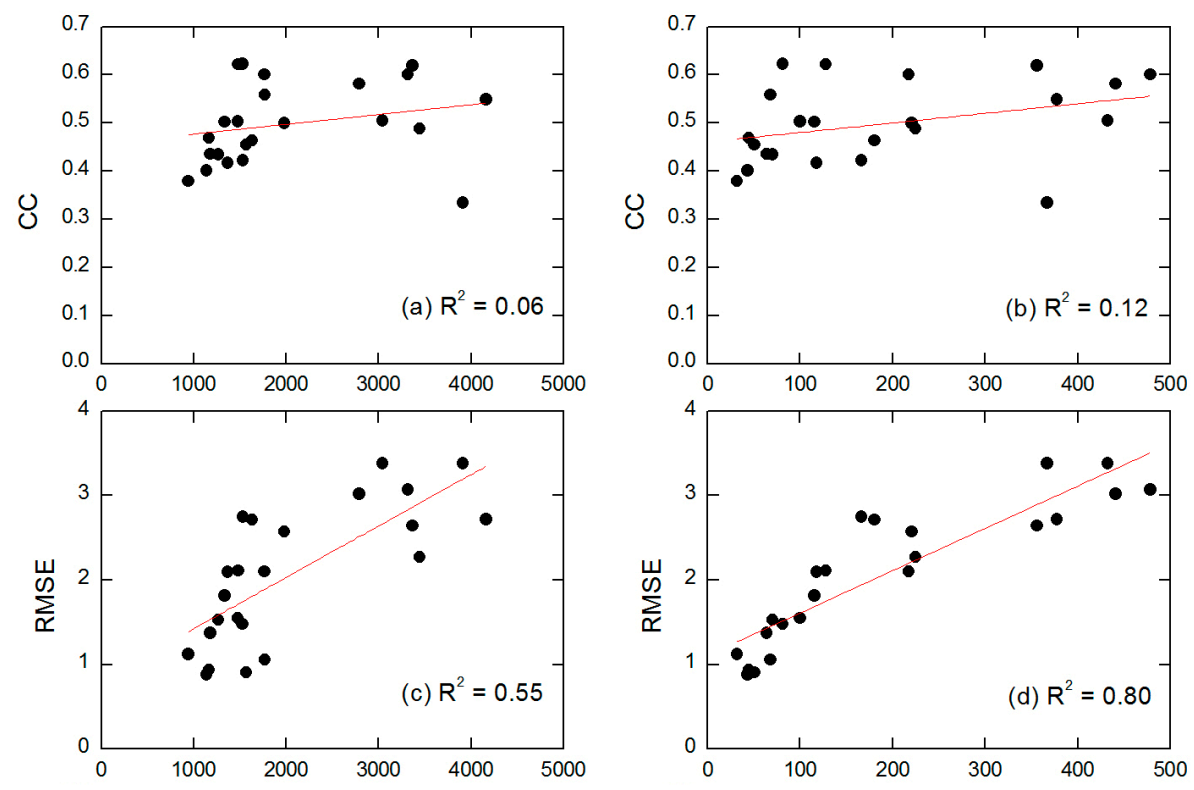

Figure 5. Cont. 

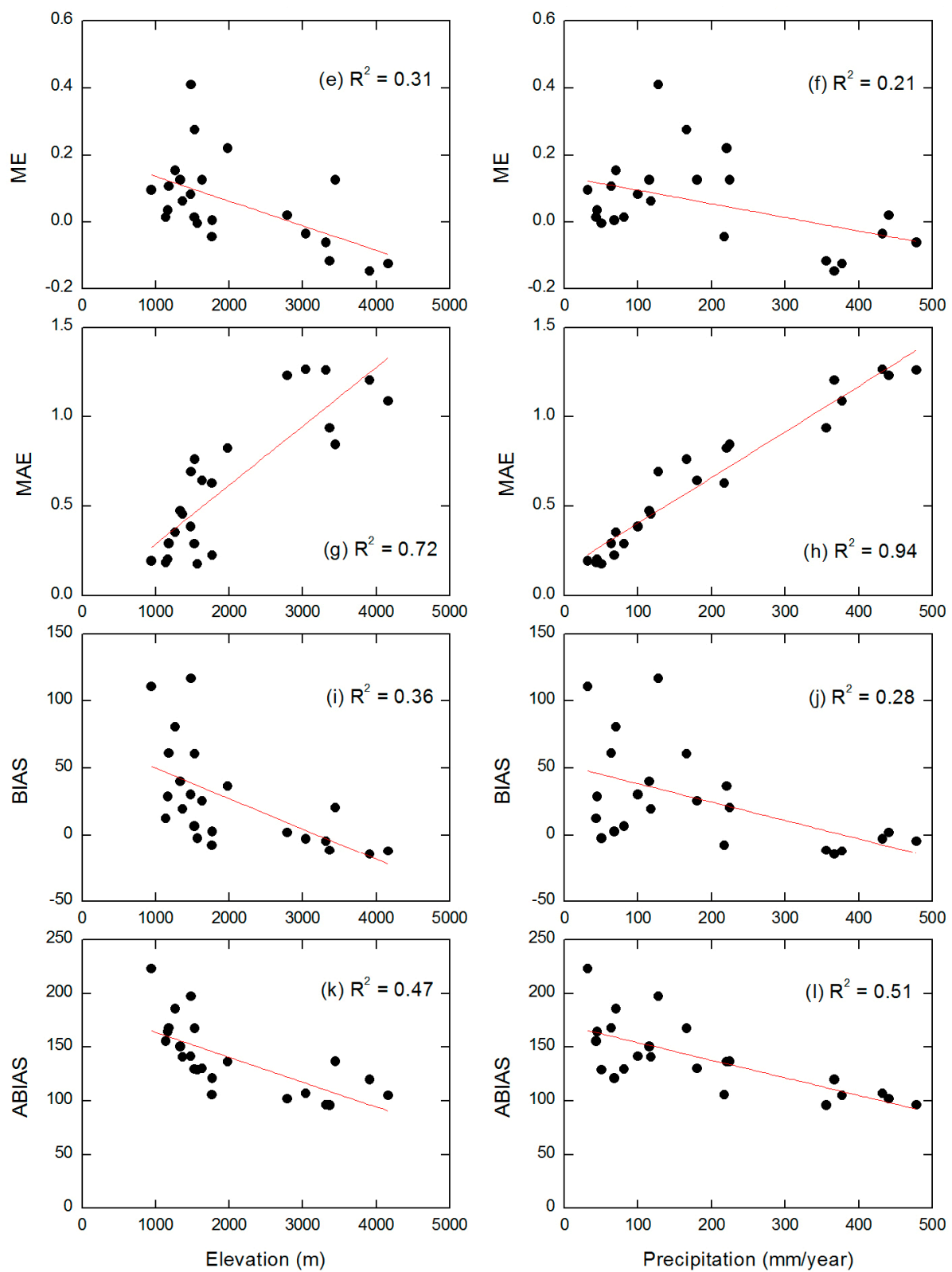

Figure 5. Scatter plots between six statistical indices and elevation/ average annual precipitation based on daily precipitation from 2009-2015 (a-1). Each dot represents a rain gauge. Red lines show the linear regression fitting line. The values of coefficient of determination $\left(R^{2}\right)$ for the linear trends are shown in the figure accordingly.

Figure 6 shows the comparison between 3B42V7 and rain gauge precipitation estimates on monthly scale. The 3B42V7 rainfall product shows an excellent agreement with the rain gauge data at monthly scale. All CC values in the 23 rain gauges are higher than 0.69 , more than 10 rain gauges' CC value are higher than 0.90 . Among the 19 sites above $1200 \mathrm{~m}$ above sea level, the CC values are all above 0.8 , except for the Hongliuhe (0.75) and Jingtai (0.73) sites. The ABias ranges from $20 \%$ to $150 \%$ (Figure 6f), lower than the daily ABias (96\% to 225\%), indicating that the accuracy of 3B42V7 rainfall product is higher on larger time scale. 


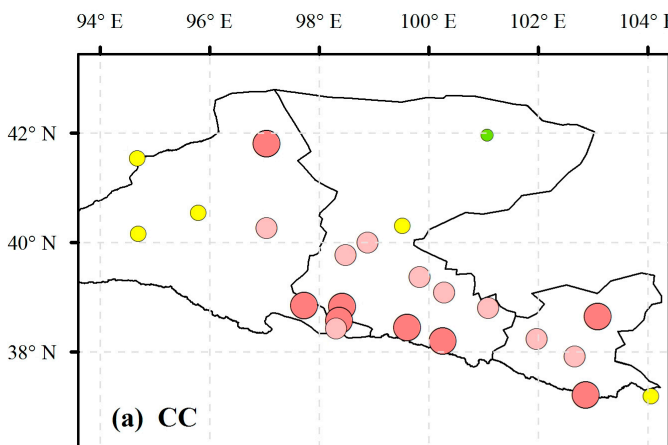

(a) $\mathrm{CC}$

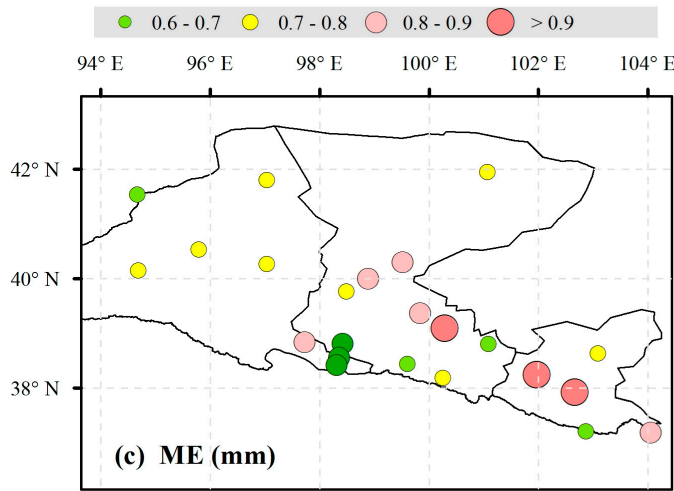

$-5--3 \bigcirc-3-0 \quad \bigcirc \quad 0-3 \bigcirc 3-5 \bigcirc 5-13$

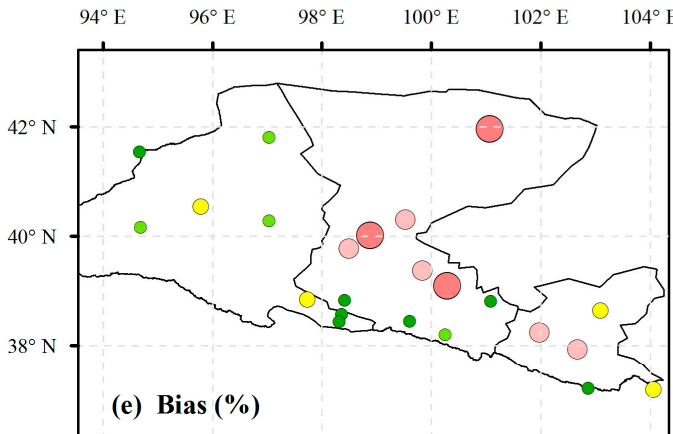

$-15-0 \bigcirc 0-15 \bigcirc 15-30 \bigcirc 30-80 \bigcirc 80-120$

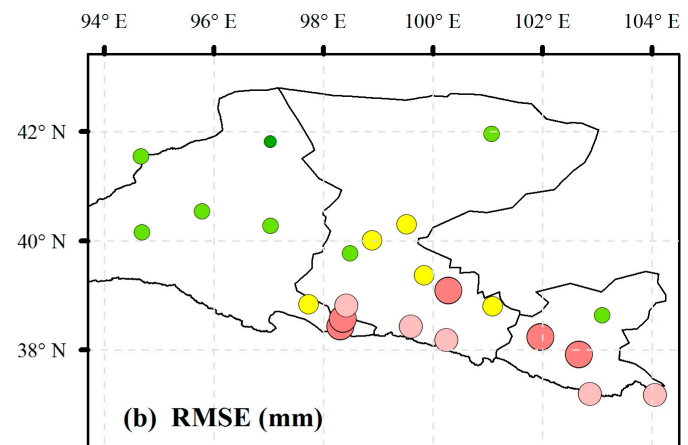

(b) RMSE (mm)

- $3-4 \bigcirc 4-8 \bigcirc 8-12 \bigcirc 12-16 \bigcirc 16-21$

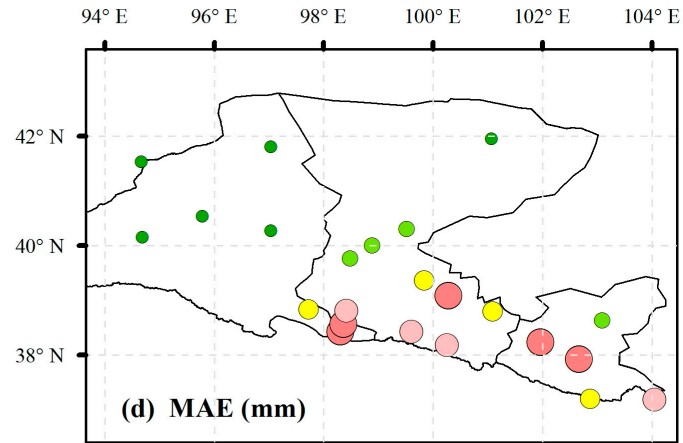

(d) MAE (mm)

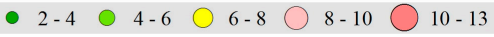

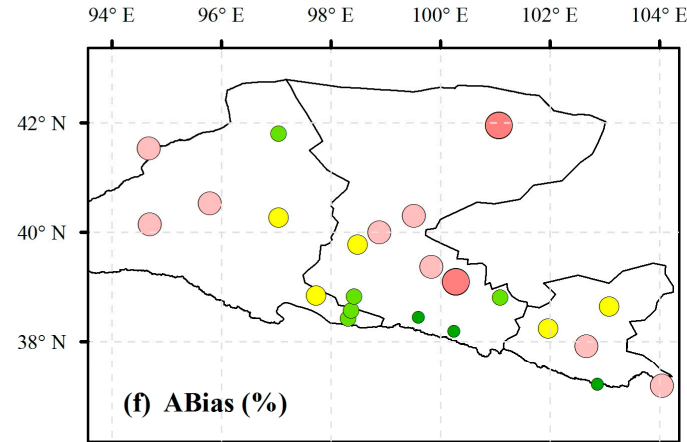

$20-30 \bigcirc 30-40 \bigcirc 40-60 \bigcirc 60-100 \bigcirc 100-150$

Figure 6. Spatial distribution of six continuous statistical indices based on monthly precipitation from 2009-2015: (a) CC, (b) RMSE, (c) ME, (d) MAE, (e) Bias, and (f) ABias.

We also examined the dependence of the six evaluation indices on elevation/average annual rainfall based on monthly precipitation in Figure 7, and similar trends with daily scale were found. It is important to note that the $\mathrm{R}^{2}$ of MAE, ABias and RMSE have a certain degree of decline compared with the daily scale, which indicates that the distribution of the error on the daily scale is more related to the elevation/rainfall.

As for the annual scale (Figure 8), the CC value (Figure 8a) shows a great degree of irregularity due to the shorter data years. It is worth noting that negative values appear at some high-altitude sites, indicating a decreasing trend of 3B42V7 with the increasing of the rain gauge data. The error magnitude of 3B42V7 measured by RMSE (Figure 8b), ME (Figure 8c) and MAE (Figure 8d) increase in quantity, but the trend of change is similar to that on the daily scale. The ABias ranges from $7 \%$ to $125 \%$ (Figure 8 f), lower than the daily ( $96 \%$ to $225 \%$ ) and monthly ( $20 \%$ to $150 \%$ ) scale. 

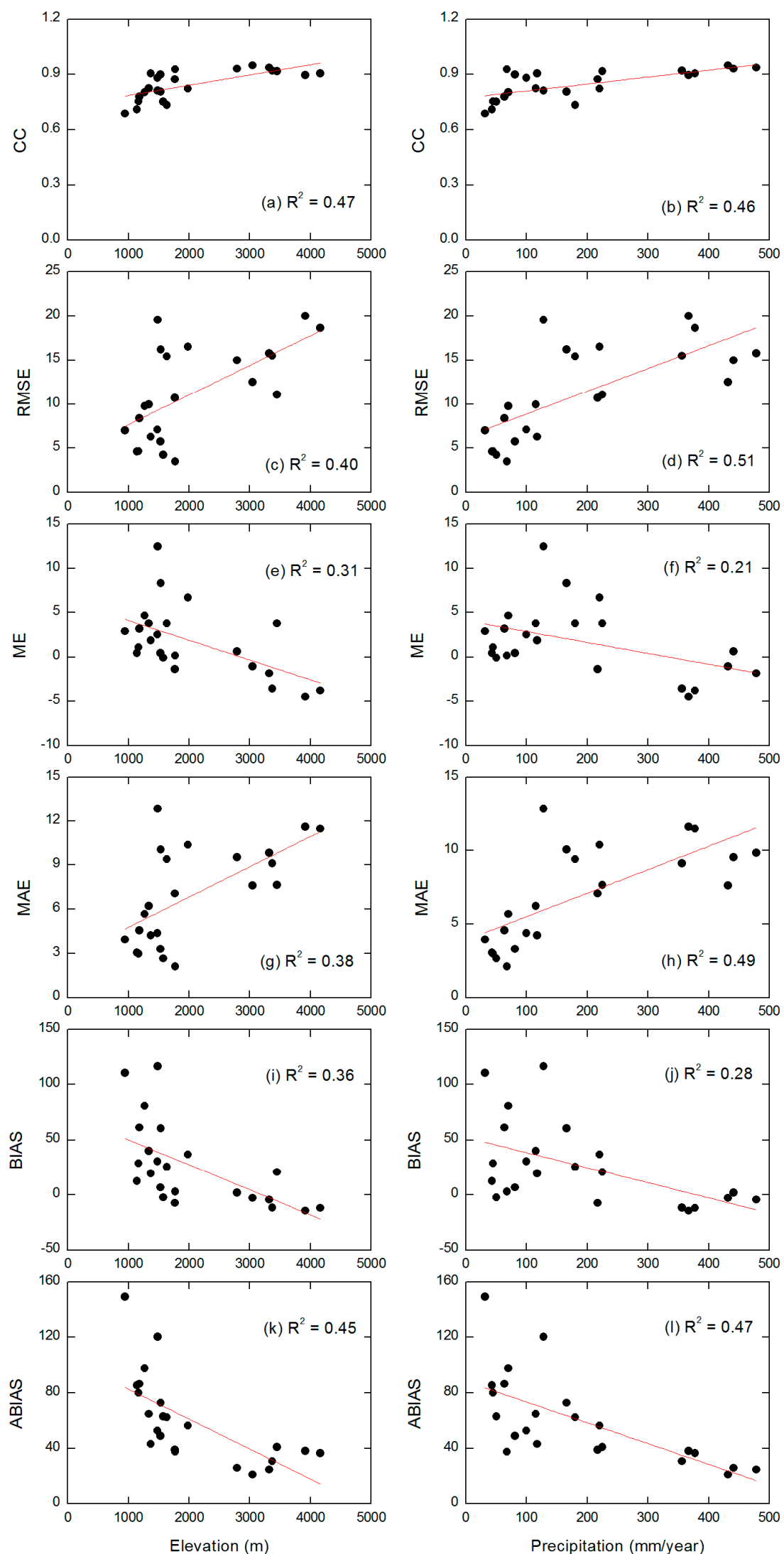

Figure 7. Scatter plots between six statistical indices and elevation/average annual precipitation based on monthly precipitation from 2009-2015 (a-1). The legend is same to Figure 5. 


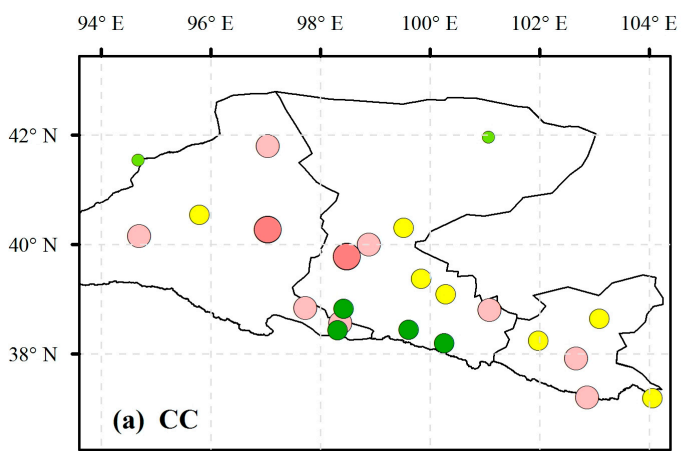

$-0.5--0.1 \bigcirc-0.1-0.1 \bigcirc 0.1-0.5 \bigcirc 0.5-0.9 \bigcirc>0.9$
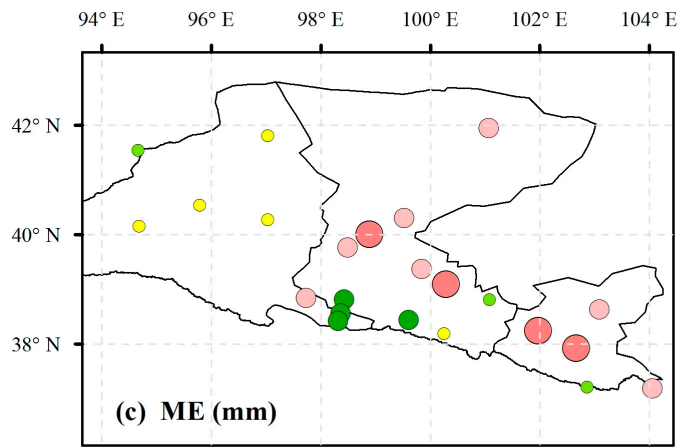

$-53--20 \bigcirc-20-0 \bigcirc 0-20 \bigcirc 20-50 \bigcirc 50-150$

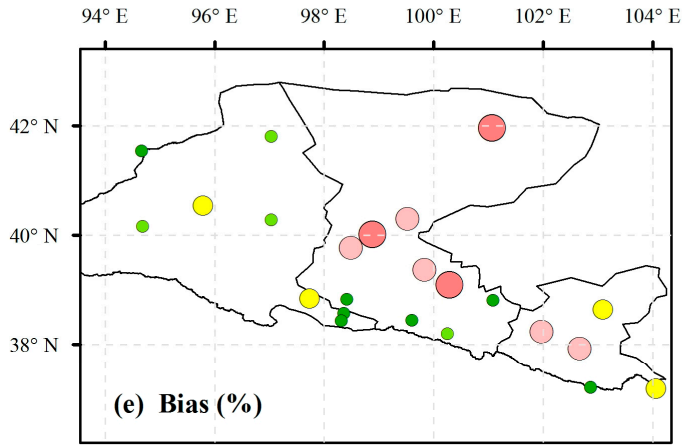

$-15-0 \bigcirc 0-15 \bigcirc 15-30 \bigcirc 30-80 \bigcirc 80-120$

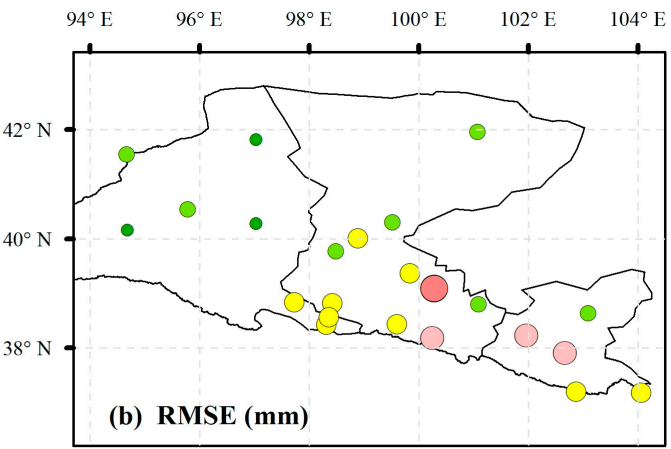

- $11-20 \bigcirc 20-50 \bigcirc 50-80 \bigcirc 80-110 \bigcirc 110-160$

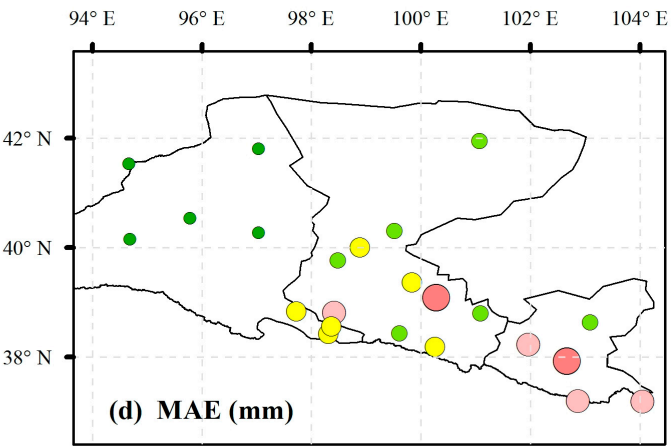

$9-20 \bigcirc 20-40 \bigcirc 40-60 \bigcirc 60-100 \bigcirc 100-150$

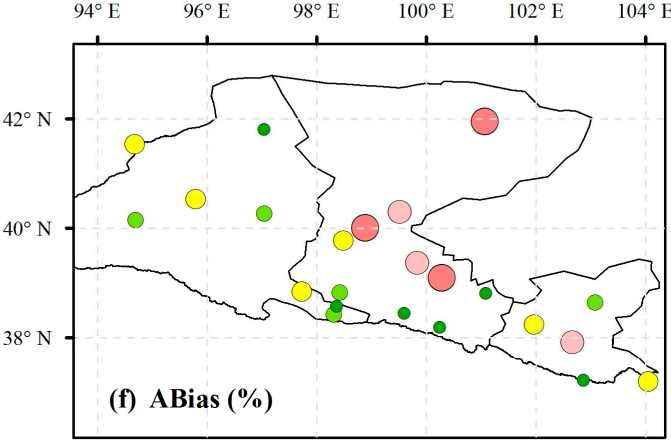

- 7-16 $\bigcirc 16-24 \bigcirc 24-40 \bigcirc 40-80 \bigcirc 80-125$

Figure 8. Spatial distribution of six continuous statistical indices based on annual precipitation from 2009-2015: (a) CC, (b) RMSE, (c) ME, (d) MAE, (e) Bias, and (f) ABias.

Figure 9 shows the linear relationship between the six evaluation metrics and elevation/rainfall based on annual precipitation. Different from the daily and monthly scales, CC shows a decreasing trend with the increasing altitude/rainfall at annual scale. The $\mathrm{R}^{2}$ of $\mathrm{CC}$ is lower than it at the monthly scale, but still higher than it at the daily scale; and $\mathrm{R}^{2}$ values for MAE, ABias and RMSE are further decreased compared to the monthly scale. It is further confirmed that the relations between evaluation metrics and altitude/rainfall is more relevant on a smaller time scale. 

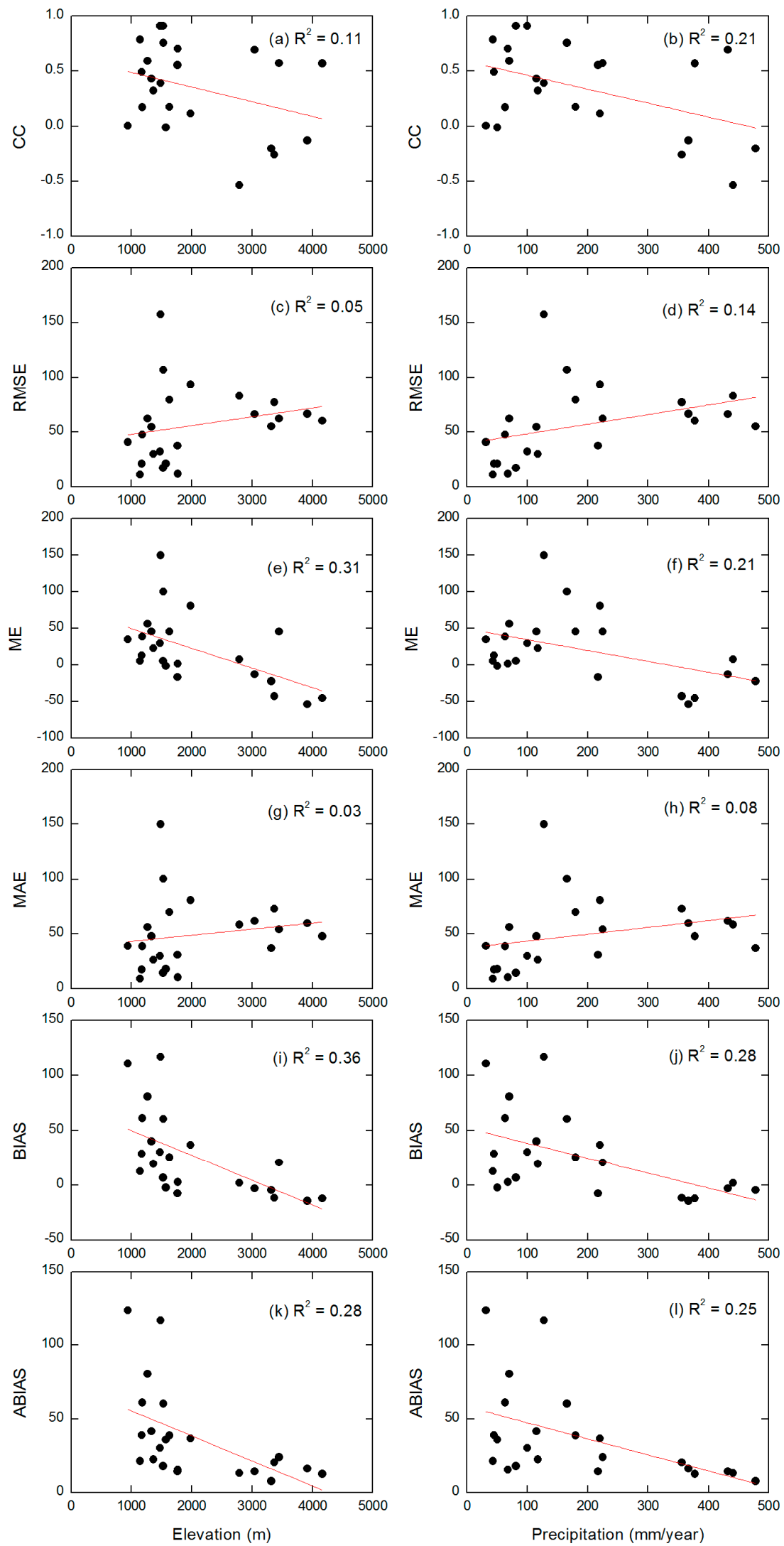

Figure 9. Scatter plots between six statistical indices and elevation/average annual precipitation based on annual precipitation from 2009-2015 (a-1). The legend is same to Figure 5. 


\subsubsection{Analysis of the Detection Capability on Rainfall Events}

The evaluation of this part mainly focuses on the ability to detect the occurrence or not of rainfall events. Based on Equations (7)-(10), the categorical statistical indices in different stations were calculated respectively. In general, the 3B42V7 rainfall product has a certain degree of detection capability for rainfall events in the Hexi region, with an average POD of 0.59 , FAR of 0.60, FBI of 1.46, and CSI of 0.32 , but the accuracy is relatively low. Figure 10 shows the spatial distribution of four categorical statistical indices based on the daily precipitation from 2009-2015. As shown in Figure 10a, the POD values ranges from $0.37-0.71$ and the high-value sites are mostly located in the southeastern mountainous areas, where the altitude and rainfall are relatively higher. The FAR values are within 0.42 to 0.81 , and sites with relatively higher elevations in the southeast show smaller FAR values (Figure 10b), indicating that 3B42V7 has a relatively small misjudgment rate of precipitation events in high-altitude areas. The FBI value is all above 1 in addition to the Hongliuhe station (0.93) (Figure 10c), indicating that the 3B42V7 has an overall overestimation of precipitation events in the Hexi region. The CSI values are all below 0.5 (Figure 10d), which means that the proportion of the precipitation events correctly detected by $3 \mathrm{~B} 42 \mathrm{~V} 7$ is less than $50 \%$ of the total detection amount.
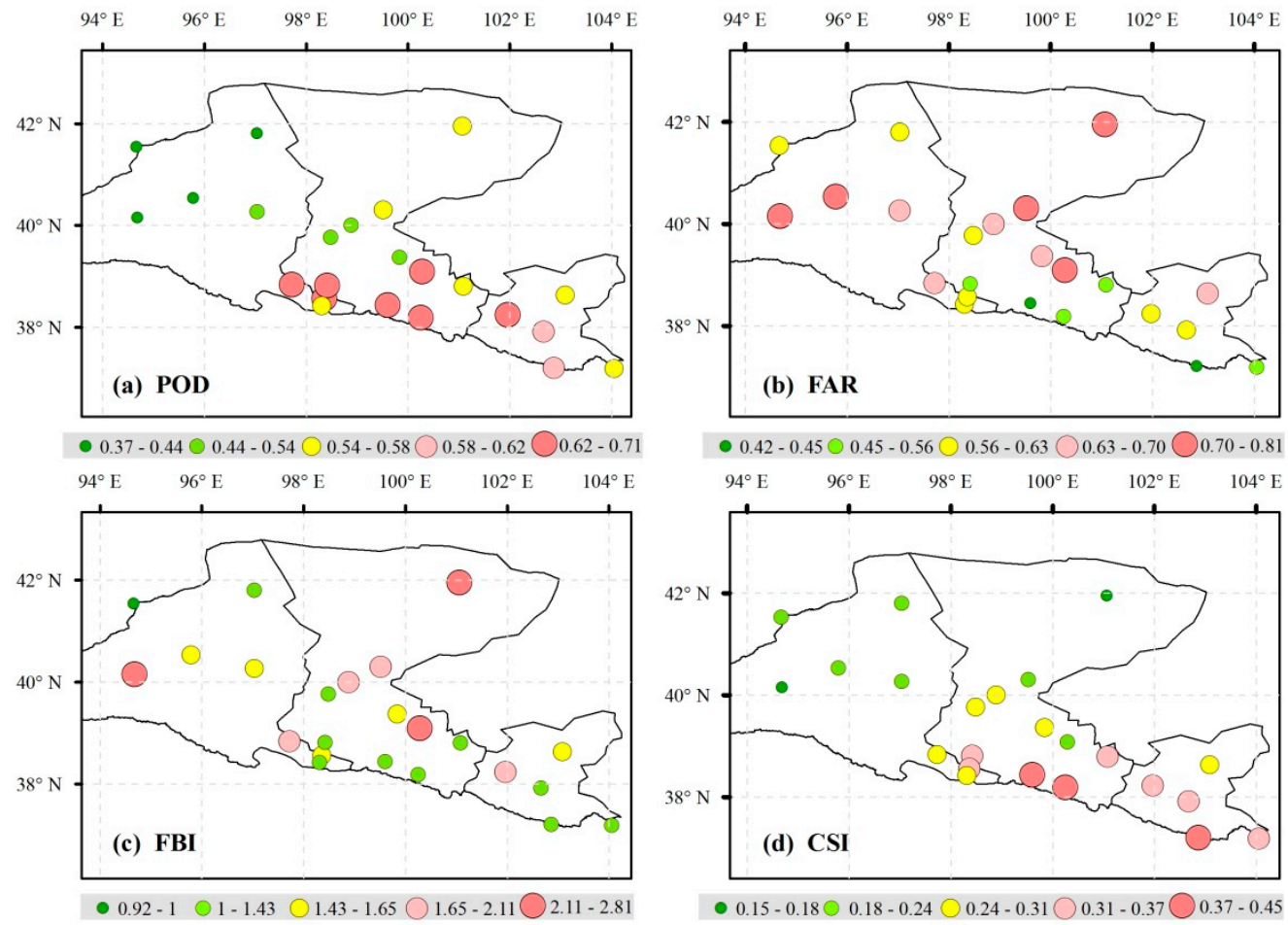

Figure 10. Spatial distribution of four categorical statistical indices based on daily precipitation from 2009-2015: (a) POD, (b) FAR, (c) FBI, (d) CSI.

In order to assess the 3B42V7 rainfall product's ability in detecting precipitation events at different magnitude, the daily rainfall was classified refer to the relevant studies $[17,45,65]$ and the actual rainfall situation in the Hexi region into six categories as follows: (I) $0-1 \mathrm{~mm} / \mathrm{d}$ (no/tiny rain); (II) 1-5 mm/d (light rain); (III) 5-10 mm/d (low moderate rain); (IV) 10-25 mm/d (high moderate rain); (V) 25-50 mm/d (low heavy rain); (VI) $>50 \mathrm{~mm} / \mathrm{d}$ (high heavy rain). The four categorical metrics were then calculated in different threshold ranges respectively. As shown in Figure 11, the POD and CSI values gradually increase at first and then decrease at Class IV, after that still show an increasing trend at Class V. The FAR is 0.82 at Class I, and become the optimal value 0 from Class II to Class VI. The FBI is 2.50 at Class I, much higher than the perfect value 1; the values from Class II to Class IV show an upward tendency, then decrease at Class V, become the perfect value 1 at Class VI. 

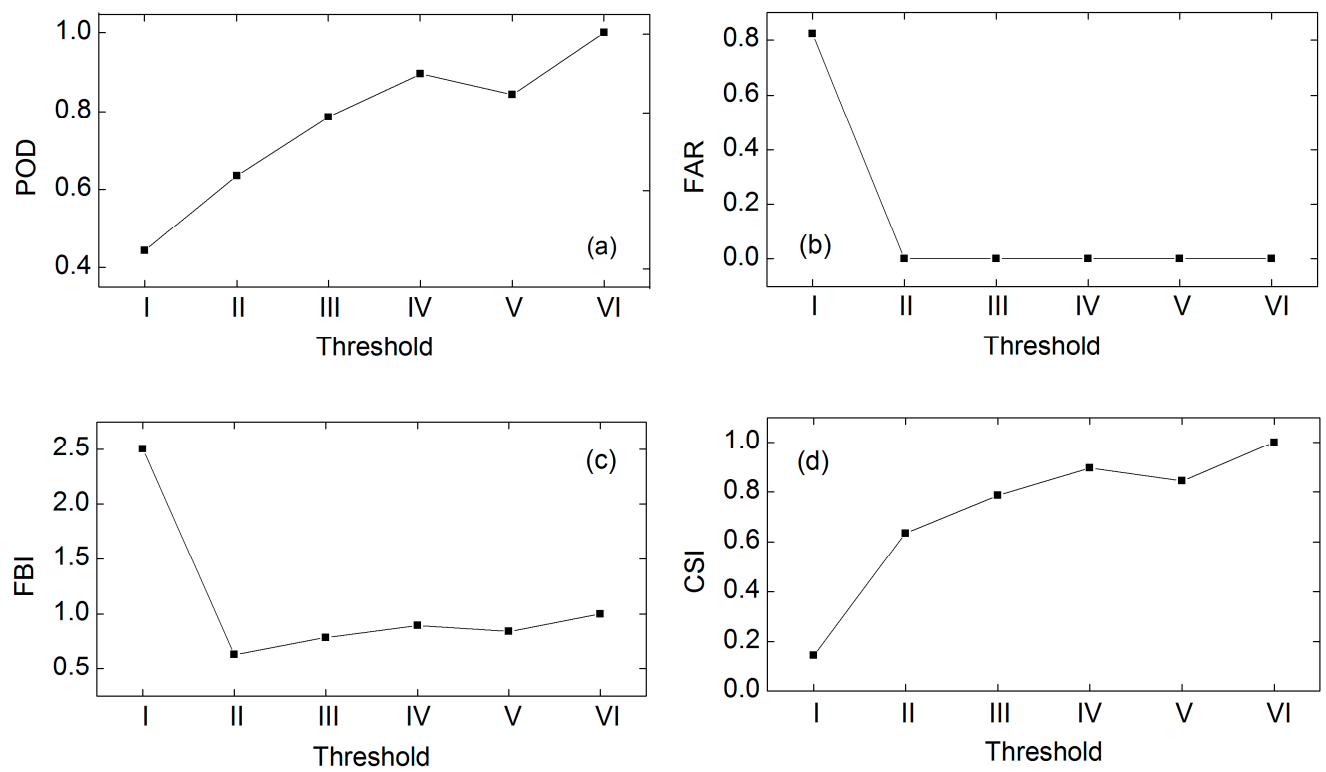

Figure 11. The overall detection capacity of TRMM 3B42V7 in different rainfall thresholds based on daily precipitation from 2009-2015: (a) POD, (b) FAR, (c) FBI, (d) CSI.

In summary, the 3B42V7 precipitation product significantly overestimated the precipitation events in the Hexi region, and the overestimation focused on the tiny rain $(0-1 \mathrm{~mm} / \mathrm{d})$, which is also the range of false alarm concentration. This is because the amount of precipitation detected by satellites is atmosphere precipitable water. Under strong evaporation in arid regions, part of the water vapor evaporates during the landing process and does not form effective precipitation. This results in a severe overestimation of precipitation in this area.

\subsection{BIAS Correction Results}

Results showed that although the 3B42V7 rainfall product can effectively capture the spatiotemporal variations of precipitation in the Hexi region, it still has considerable errors compared with ground observations. Since precipitation inputs are one of the most important variables for climatic and hydrologic studies, bias correction of 3B42V7 is required before applied to researches.

Among the 23 stations in the Hexi region we selected five stations as verification points and the remaining 18 sites performed bias correction. The bias corrector factor $\left(K_{i}\right)$ is calculated based on the accumulated monthly precipitation measured at each station (Equation (11)). Then, the corrected 3B42V7 monthly precipitation at the location $i$ can be calculated based on Equation (12). In order to verify the efficacy of this correction method, the Relative Bias and RMSE were calculated for both original and bias-corrected 3B42V7 rainfall product (Table 4). Results showed that the data quality of the bias-corrected 3B42V7 product has been significantly improved, except for stations with relatively low initial Bias such as Hongliuhe, Yumenzhen and Qilian.

By using the inverse distance weighting interpolation method, the $K$ value distribution map for 3B42V7 of the whole Hexi region was obtained (Figure 12). The bias corrector factor in the Hexi region is between 0.47 and 1.14, showing a trend of increasing from north to south. We then extracted the bias corrector factors for the 5 verification stations from the $K$ values distribution map. Additionally, the bias-corrected monthly 3B42V7 was calculated based on these $K$ values. Table 5 shows the bias correction results of the verification stations. Compared with the original data, the Bias and RMSE values for bias-corrected 3B42V7 of the five verification stations all show a certain degree of reduction. Therefore, the bias corrector factors obtained by above method in the Hexi region are considered credible and can be used for bias correction of 3B42V7 rainfall product across the whole basin. As an example, the graphical 
comparison between stations, original 3B42V7 and bias-corrected 3B42V7 of partial stations is shown in Figure 13 (including two experimental stations and two verification stations).

Table 4. Bias correction of annual rainfall based on the monthly correction, 3B42V7 vs. experimental stations.

\begin{tabular}{|c|c|c|c|c|c|c|c|c|}
\hline \multirow[b]{2}{*}{$\begin{array}{l}\text { Experimental } \\
\text { Station }\end{array}$} & \multirow{2}{*}{$\begin{array}{c}\text { Ground Data, } \\
\text { Annual } \\
\text { Rainfall } \\
\text { (mm/year) }\end{array}$} & \multicolumn{3}{|c|}{ Original 3B42V7 } & \multirow[b]{2}{*}{$\begin{array}{l}\text { Monthly } \\
\text { Bias } \\
\text { Corrector }\end{array}$} & \multicolumn{3}{|c|}{ Corrected 3B42V7 } \\
\hline & & $\begin{array}{c}\text { Annual } \\
\text { Rainfall } \\
\text { (mm/year) }\end{array}$ & Bias (\%) & $\begin{array}{c}\text { RMSE } \\
\text { (mm/year) }\end{array}$ & & $\begin{array}{c}\text { Annual } \\
\text { Rainfall } \\
\text { (mm/year) }\end{array}$ & Bias (\%) & $\begin{array}{c}\text { RMSE } \\
\text { (mm/year) }\end{array}$ \\
\hline Ejina & 31.63 & 66.61 & 110.60 & 40.67 & 0.47 & 42.39 & 34.04 & 18.56 \\
\hline Hongliuhe & 50.39 & 49.09 & $-2.58^{1}$ & 20.83 & 1.03 & 56.68 & 12.49 & 21.01 \\
\hline Mazongshan & 68.06 & 69.85 & 2.63 & 11.93 & 0.97 & 68.59 & 0.78 & 11.57 \\
\hline Dunhuang & 43.10 & 48.41 & 12.33 & 11.23 & 0.89 & 45.65 & 5.92 & 9.27 \\
\hline Yumenzhen & 80.87 & 86.16 & 6.54 & 17.34 & 0.94 & 88.46 & 9.38 & 17.25 \\
\hline Dingxin & 63.37 & 101.98 & 60.92 & 47.41 & 0.62 & 69.93 & 10.36 & 22.39 \\
\hline Jiuquan & 99.54 & 129.56 & 30.15 & 32.08 & 0.77 & 100.83 & 1.29 & 10.47 \\
\hline Gaotai & 115.17 & 161.01 & 39.80 & 54.37 & 0.72 & 121.33 & 5.34 & 28.72 \\
\hline Yeniugou & 478.59 & 456.14 & -4.69 & 55.15 & 1.05 & 482.82 & 0.89 & 50.80 \\
\hline Qilian & 440.83 & 448.33 & 1.70 & 82.75 & 0.98 & 453.67 & 2.91 & 82.09 \\
\hline Shandan & 217.40 & 200.90 & -7.59 & 37.14 & 1.08 & 220.45 & 1.40 & 34.56 \\
\hline Yongchang & 220.30 & 300.72 & 36.50 & 93.57 & 0.73 & 228.00 & 3.49 & 45.79 \\
\hline Minqin & 117.51 & 140.14 & 19.26 & 29.77 & 0.84 & 119.72 & 1.88 & 18.00 \\
\hline Wushaoling & 432.07 & 419.22 & -2.97 & 65.84 & 1.03 & 443.24 & 2.59 & 64.45 \\
\hline Jingtai & 180.37 & 226.19 & 25.40 & 79.29 & 0.80 & 196.56 & 8.98 & 61.59 \\
\hline PG-3446 & 224.91 & 270.78 & 20.39 & 62.02 & 0.83 & 229.72 & 2.14 & 39.42 \\
\hline PG-3915 & 367.01 & 313.32 & -14.63 & 66.31 & 1.17 & 368.53 & 0.41 & 43.29 \\
\hline PG-4164 & 377.52 & 331.97 & -12.06 & 59.92 & 1.14 & 378.12 & 0.16 & 43.21 \\
\hline
\end{tabular}

${ }^{1}$ Gray numbers indicate stations with increased Bias after correction.

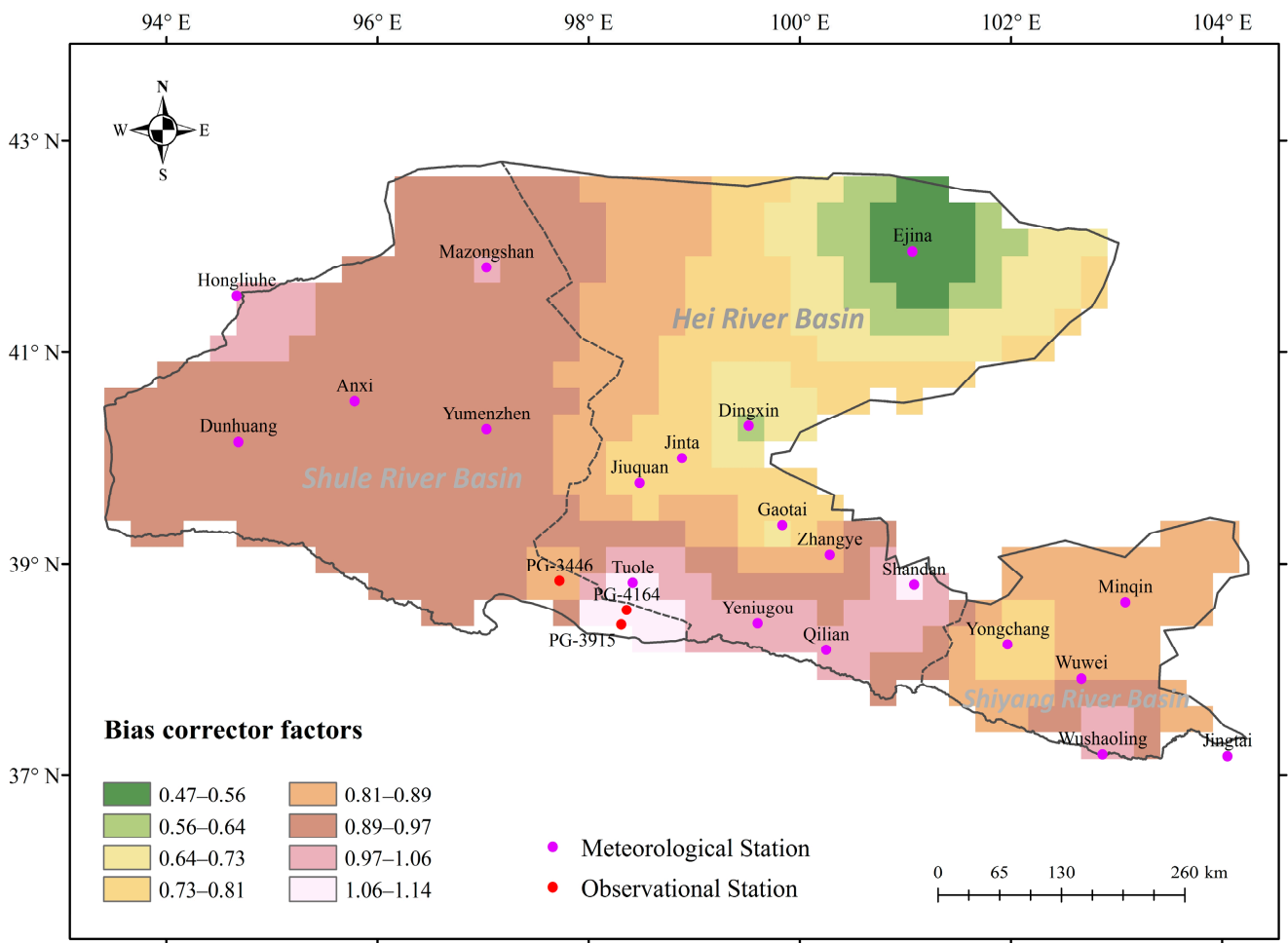

Figure 12. Spatial distribution of bias corrector factors at monthly scale across the Hexi region. 
Table 5. Bias correction of annual rainfall based on the monthly correction, 3B42V7 vs. verification stations.

\begin{tabular}{|c|c|c|c|c|c|c|c|c|}
\hline \multirow[b]{2}{*}{$\begin{array}{c}\text { Verification } \\
\text { Station }\end{array}$} & \multirow{2}{*}{$\begin{array}{c}\text { Ground Data, } \\
\text { Annual } \\
\text { Rainfall } \\
\text { (mm/year) }\end{array}$} & \multicolumn{3}{|c|}{ Original 3B42V7 } & \multirow{2}{*}{$\begin{array}{l}\text { Monthly } \\
\text { Bias } \\
\text { Corrector }\end{array}$} & \multicolumn{3}{|c|}{ Corrected 3B42V7 } \\
\hline & & $\begin{array}{c}\text { Annual } \\
\text { Rainfall } \\
\text { (mm/year) }\end{array}$ & $\begin{array}{l}\text { Bias } \\
(\%)\end{array}$ & $\begin{array}{c}\text { RMSE } \\
\text { (mm/year) }\end{array}$ & & $\begin{array}{c}\text { Annual } \\
\text { Rainfall } \\
\text { (mm/year) }\end{array}$ & Bias (\%) & $\begin{array}{c}\text { RMSE } \\
\text { (mm/year) }\end{array}$ \\
\hline Anxi & 44.63 & 57.48 & 28.81 & 20.79 & 0.93 & 53.56 & 20.02 & 18.21 \\
\hline Jinta & 69.74 & 125.95 & 80.59 & 61.90 & 0.79 & 99.83 & 43.14 & 37.64 \\
\hline Tuole & 355.90 & 313.26 & -11.98 & 76.72 & 1.04 & 325.80 & -8.46 & 72.20 \\
\hline Zhangye & 128.07 & 277.72 & 116.85 & 157.40 & 0.82 & 226.46 & 76.82 & 106.30 \\
\hline Wuwei & 165.87 & 266.13 & 60.44 & 106.79 & 0.88 & 233.43 & 40.73 & 76.98 \\
\hline
\end{tabular}

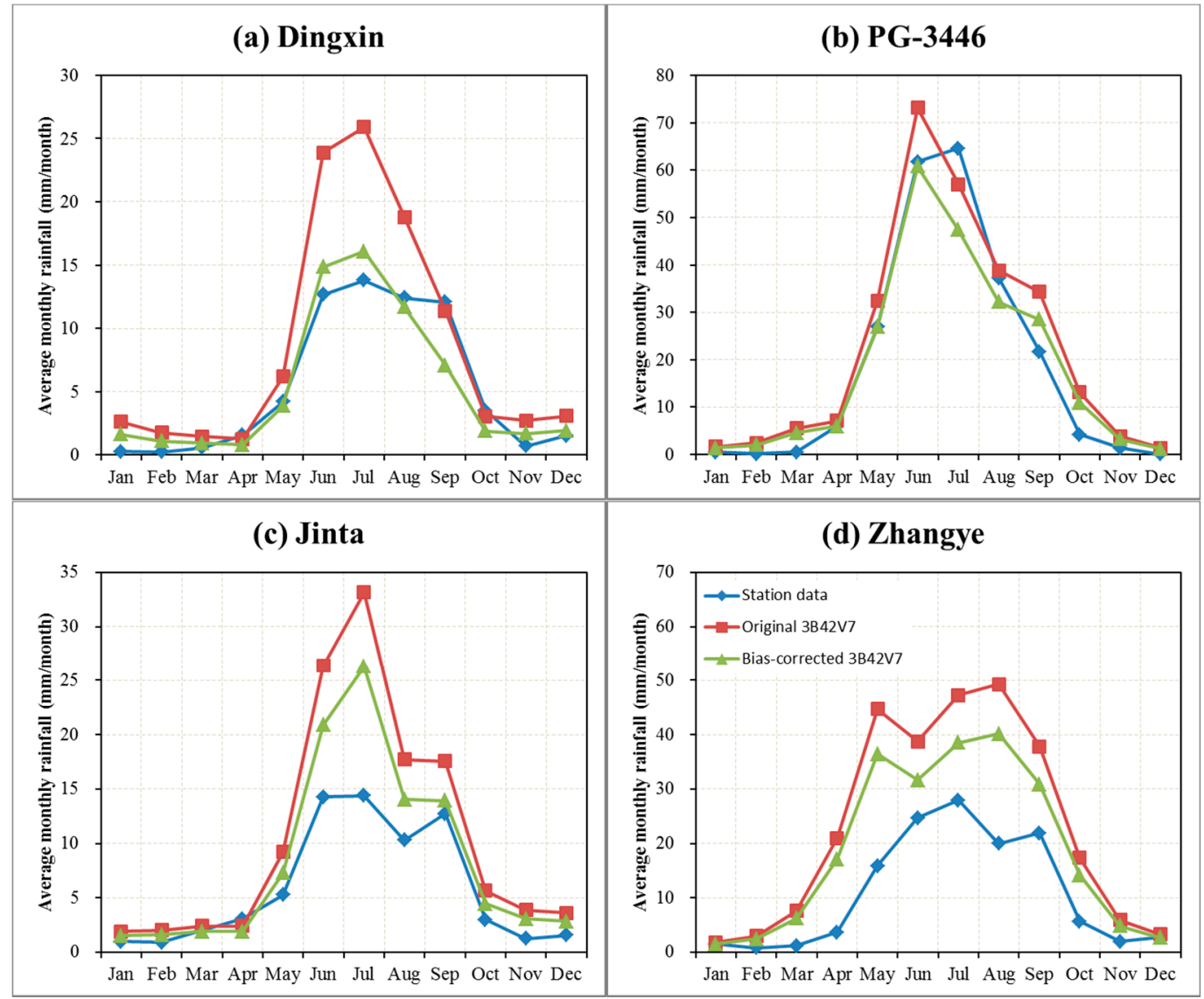

Figure 13. Average monthly bias-corrected 3B42V7 rainfall data over 2009-2015 compared with stations and original 3B42V7 data; (a,b) experimental stations; (c,d) verification stations.

Since various rainfall-runoff simulations were established using only daily precipitation data, the bias-corrected 3B42V7 monthly precipitation values were then disaggregated into daily time series ones for each grid. To achieve this, the temporal disaggregation coefficient $\left(f_{i}\right)$ was first derived from the station daily time series based on the Equation (13). The $f_{i, d, m}$ ratios were then applied back to the bias-corrected 3B42V7 monthly values to calculate the daily series estimates (Equation (14)).

Similar to the monthly scale, we also show an example of two experimental stations and two verification stations to illustrate the validity of this disaggregation method for daily time scale. Figure 14 shows the correlation between the daily precipitation data at stations and their corresponding bias-corrected daily 3B42V7 values. On daily time scale, the correlation of the bias-corrected 3B42V7 rainfall product compared with ground observations increased significantly. The coefficient of determination $\left(\mathrm{R}^{2}\right)$ increased from 0.21 to 0.92 for Dingxin station, 0.43 to 0.91 for PG-3446 station, 0.32 to 0.94 for Jinta station and 0.43 to 0.89 for Zhangye station, respectively. Considering the relatively 
high bias values and low correlation coefficients of the original data the daily time scale, the method of correcting 3B42V7 product using the monthly mean deviation is considered to be feasible in the Hexi region.
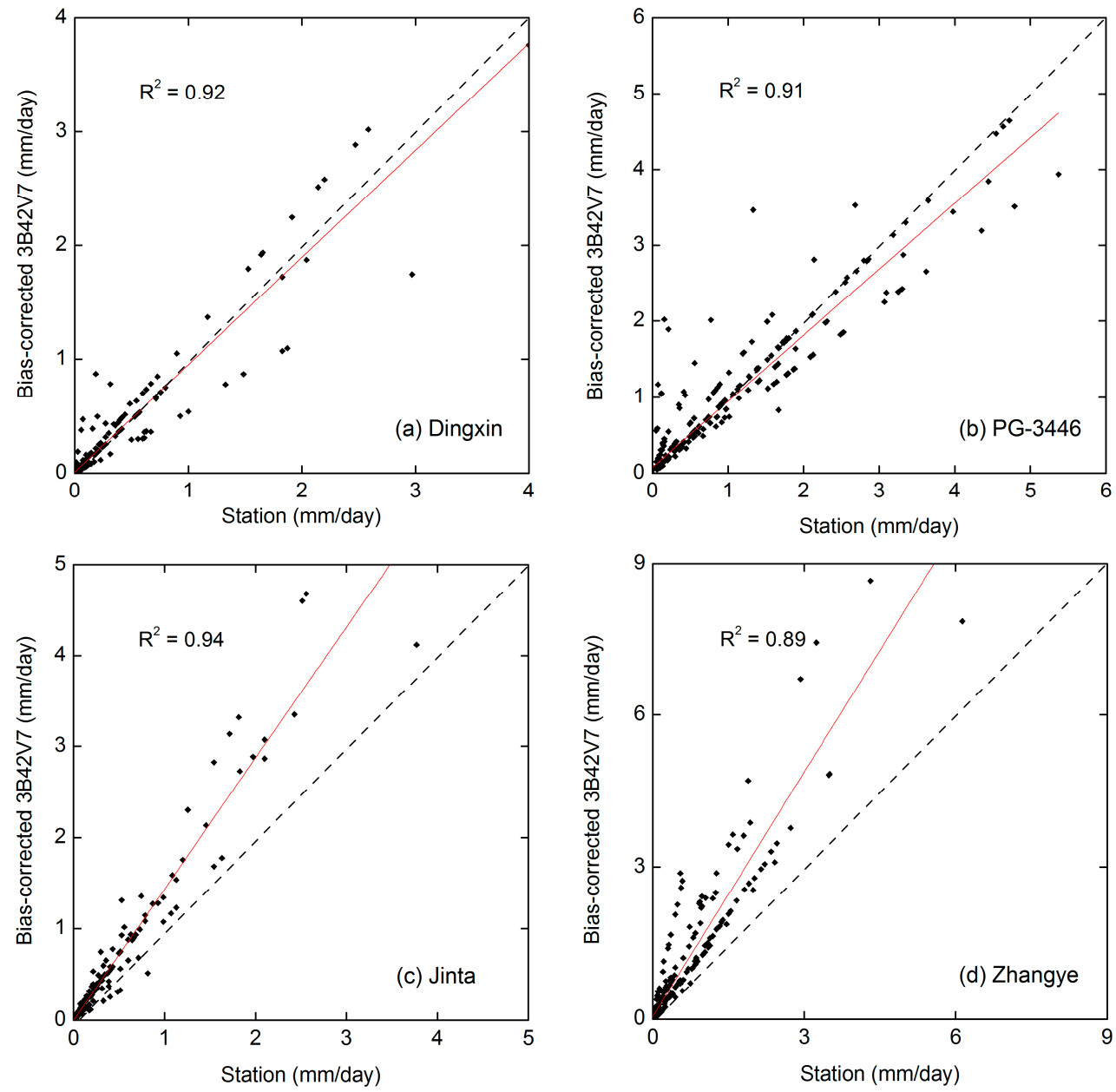

Figure 14. Comparison of average daily precipitation over 2009-2015 measured by stations and bias-corrected 3B42V7; (a,b) experimental stations; (c,d) verification stations. The legend is the same as Figure 2.

\section{Conclusions}

Satellite rainfall products play an important role in climate and hydrological research, particularly for the remote arid regions with adverse natural conditions. This study assesses the TRMM 3B42V7 rainfall product based on 23 meteorological stations over the Hexi region in northwestern China during 2009-2015. The daily, monthly, seasonal and annual precipitation time series were analyzed. Both the error and detection capabilities were evaluated and quantified through continuous and categorical statistical indices at different time scales. The major conclusions can be summarized as follows:

1. The 3B42V7 rainfall product can effectively capture the spatiotemporal variations of precipitation in the Hexi region and overestimate the precipitation with Bias of $11.16 \%$, and ABias of $121.99 \%$, $43.80 \%, 25.87 \%$ at daily, monthly and annual respectively. Compared with ground observations, 3B42V7 shows relatively low correlation at daily time series than at monthly and annual time series. Precipitation in the Hexi region has an obvious seasonal distribution characteristic. The 3B42V7 performs much better during warm seasons (summer and autumn) than in cold seasons (spring and winter). 
2. Similar spatial distribution characteristics of evaluation metrics are found at daily, monthly and annual time scales. The 3B42V7 is more likely to underestimate the precipitation in high-altitude mountainous areas and overestimate the precipitation in low-elevation areas. The 3B42V7 shows better correlation with rain gauges located in the southern mountainous and central oasis areas than in the northern extreme arid region. The error magnitude measured by RMSE (MAE) exhibited a significant decreasing trend from south to north, east to west.

3. Altitude and rainfall are important factors for the different distribution of the evaluation indexes. Absolute error distribution characteristics (MAE, ABias and RMSE) of 3B42V7 have better correlation with altitude and rainfall than the relative error indexes (CC, ME and Bias). The distribution of the error on the daily scale is more related to the elevation and rainfall than in monthly and annual scale.

4. The ability of $3 \mathrm{~B} 42 \mathrm{~V} 7$ to detect precipitation events increases with the increasing of precipitation intensity. The 3B42V7 significantly overestimates the precipitation events in the Hexi region with an average POD of 0.59 , FAR of 0.60 , FBI of 1.46, and CSI of 0.32 . The overestimation is mainly concentrated in tiny rain $(0-1 \mathrm{~mm} / \mathrm{d})$. Better detection capabilities can be found at high-altitude areas.

5. The bias-corrected 3B42V7 has been significantly improved in both the monthly and daily time series. The method of correcting 3B42V7 product using the monthly mean deviation is considered to be feasible and can be used for bias correction of 3B42V7 rainfall product across the whole Hexi region.

The findings of this study suggest that although the 3B42V7 rainfall product can capture the temporal and spatial variations of precipitation in the Hexi region, it still has considerable errors compared to ground observations. The bias-corrected monthly, annual and disaggregated daily 3B42V7 data has good reference value for climate and hydrological applications. However, in the data correction process, we ignore the influence of topographic factors, and the correction method has a strong dependence on ground observations. Further research should strengthen the role of topographical factors in the data correction process, find better data correction methods, and apply the revised data to regional hydrological simulation.

Author Contributions: All authors contributed to the design and development of the work. Y.D. and X.W. conceived and designed the research; X.W. collected and carried out the data analysis, outlined the finding and wrote the manuscript; C.Z. and J.W. made contributions in editing of the manuscript.

Funding: This research was funded by the National Natural Science Foundation of China (Grant Nos. 41730751; 41771087 and 41471060).

Acknowledgments: The authors wish to thank the Meteorological Data Center of China Meteorological Administration and Tropical Rainfall Measuring Mission (TRMM) Multi-satellite Precipitation Analysis (TMPA) developers for providing the climate data. The authors would like to thank the Editors and the reviewers for their crucial comments that improved the quality of this paper.

Conflicts of Interest: The authors declare no conflicts of interest.

\section{References}

1. Intergovernmental Panel on Climate Change (IPCC). Contribution of Working Group I to the Fifth Assessment Report of the Intergovernmental Panel on Climate Change; Stocker, T.F., Ed.; Cambridge University Press: Cambridge, UK, 2013.

2. Son, K.; Bae, D. Drought analysis according to shifting of climate zones to arid climate zone over Asia monsoon region. J. Hydrol. 2015, 529, 1021-1029. [CrossRef]

3. Deng, X.; Shi, Q.; Zhang, Q.; Shi, C.; Yin, F. Impacts of land use and land cover changes on surface energy and water balance in the Heihe River Basin of China, 2000-2010. Phys. Chem. Earth Parts A/B/C 2015, 79-82, 2-10. [CrossRef]

4. Allan, R.P.; Soden, B.J. Atmospheric warming and the amplification of precipitation extremes. Science 2008, 321, 1481-1484. [CrossRef] [PubMed] 
5. Zhao, R.; Chen, Y.; Shi, P.; Zhang, L.; Pan, J.; Zhao, H. Land use and land cover change and driving mechanism in the arid inland river basin: A case study of Tarim River, Xinjiang, China. Environ. Earth Sci. 2013, 68, 591-604. [CrossRef]

6. Ji, X.; Kang, E.; Chen, R.; Zhao, W.; Zhang, Z.; Jin, B. The impact of the development of water resources on environment in arid inland river basins of Hexi region, Northwestern China. Environ. Geol. 2006, 50, 793-801. [CrossRef]

7. Kang, E.S.; Cheng, G.D.; Lan, Y.C.; Jin, H.J. A model for simulating the response of runoff from the mountainous watersheds of inland river basins in the arid area of northwest China to climatic changes. Sci. China Ser. D-Earth Sci. 1999, 42, 52-63. [CrossRef]

8. Ruan, H.; Zou, S.; Yang, D.; Wang, Y.; Yin, Z.; Lu, Z.; Li, F.; Xu, B. Runoff Simulation by SWAT Model Using High-Resolution Gridded Precipitation in the Upper Heihe River Basin, Northeastern Tibetan Plateau. Water 2017, 9, 866. [CrossRef]

9. Jiang, S.; Zhou, M.; Ren, L.; Cheng, X.; Zhang, P. Evaluation of latest TMPA and CMORPH satellite precipitation products over Yellow River Basin. Water Sci. Eng. 2016, 9, 87-96. [CrossRef]

10. Li, Q.; Yang, G. Temporal Distribution Characteristics of Alpine Precipitation and Their Vertical Differentiation: A Case Study from the Upper Shule River. Water 2017, 9, 284. [CrossRef]

11. Sun, R.; Yuan, H.; Liu, X.; Jiang, X. Evaluation of the latest satellite-gauge precipitation products and their hydrologic applications over the Huaihe River basin. J. Hydrol. 2016, 536, 302-319. [CrossRef]

12. Prakash, S.; Mitra, A.K.; AghaKouchak, A.; Pai, D.S. Error characterization of TRMM Multisatellite Precipitation Analysis (TMPA-3B42) products over India for different seasons. J. Hydrol. 2015, 529, 1302-1312. [CrossRef]

13. Meng, J.; Li, L.; Hao, Z.; Wang, J.; Shao, Q. Suitability of TRMM satellite rainfall in driving a distributed hydrological model in the source region of Yellow River. J. Hydrol. 2014, 509, 320-332. [CrossRef]

14. Tan, M.L.; Tan, K.C.; Chua, V.P.; Chan, N.W. Evaluation of TRMM Product for Monitoring Drought in the Kelantan River Basin, Malaysia. Water 2017, 9, 57. [CrossRef]

15. Mohd Zad, S.; Zulkafli, Z.; Muharram, F. Satellite Rainfall (TRMM 3B42-V7) Performance Assessment and Adjustment over Pahang River Basin, Malaysia. Remote Sens. 2018, 10, 388. [CrossRef]

16. Jiang, Q.; Li, W.; Wen, J.; Qiu, C.; Sun, W.; Fang, Q.; Xu, M.; Tan, J. Accuracy Evaluation of Two High-Resolution Satellite-Based Rainfall Products: TRMM 3B42V7 and CMORPH in Shanghai. Water 2018, 10, 40. [CrossRef]

17. Xu, R.; Tian, F.; Yang, L.; Hu, H.; Lu, H.; Hou, A. Ground validation of GPM IMERG and TRMM 3B42V7 rainfall products over southern Tibetan Plateau based on a high-density rain gauge network. J. Geophys. Res. Atmos. 2017, 122, 910-924. [CrossRef]

18. Jiang, S.; Ren, L.; Yong, B.; Hong, Y.; Yang, X.; Yuan, F. Evaluation of latest TMPA and CMORPH precipitation products with independent rain gauge observation networks over high-latitude and low-latitude basins in China. Chin. Geogr. Sci. 2016, 26, 439-455. [CrossRef]

19. Cai, Y.; Jin, C.; Wang, A.; Guan, D.; Wu, J.; Yuan, F.; Xu, L. Comprehensive precipitation evaluation of TRMM 3B42 with dense rain gauge networks in a mid-latitude basin, northeast, China. Theor. Appl. Climatol. 2016, 126, 659-671. [CrossRef]

20. Gebere, S.; Alamirew, T.; Merkel, B.; Melesse, A. Performance of High Resolution Satellite Rainfall Products over Data Scarce Parts of Eastern Ethiopia. Remote Sens. 2015, 7, 11639-11663. [CrossRef]

21. Tong, K.; Su, F.; Yang, D.; Hao, Z. Evaluation of satellite precipitation retrievals and their potential utilities in hydrologic modeling over the Tibetan Plateau. J. Hydrol. 2014, 519, 423-437. [CrossRef]

22. Li, X.; Zhang, Q.; Xu, C. Suitability of the TRMM satellite rainfalls in driving a distributed hydrological model for water balance computations in Xinjiang catchment, Poyang lake basin. J. Hydrol. 2012, 426-427, 28-38. [CrossRef]

23. Yang, N.; Zhang, K.; Hong, Y.; Zhao, Q.; Huang, Q.; Xu, Y.; Xue, X.; Chen, S. Evaluation of the TRMM multisatellite precipitation analysis and its applicability in supporting reservoir operation and water resources management in Hanjiang basin, China. J. Hydrol. 2017, 549, 313-325. [CrossRef]

24. Katiraie-Boroujerdy, P.; Akbari Asanjan, A.; Hsu, K.; Sorooshian, S. Intercomparison of PERSIANN-CDR and TRMM-3B42V7 precipitation estimates at monthly and daily time scales. Atmos. Res. 2017, 193, 36-49. [CrossRef]

25. Qiao, L.; Hong, Y.; Chen, S.; Zou, C.B.; Gourley, J.J.; Yong, B. Performance assessment of the successive Version 6 and Version 7 TMPA products over the climate-transitional zone in the southern Great Plains, USA. J. Hydrol. 2014, 513, 446-456. [CrossRef] 
26. Li, Z.; Yang, D.; Hong, Y. Multi-scale evaluation of high-resolution multi-sensor blended global precipitation products over the Yangtze River. J. Hydrol. 2013, 500, 157-169. [CrossRef]

27. Worqlul, A.W.; Ayana, E.K.; Maathuis, B.H.P.; MacAlister, C.; Philpot, W.D.; Osorio Leyton, J.M.; Steenhuis, T.S. Performance of bias corrected MPEG rainfall estimate for rainfall-runoff simulation in the upper Blue Nile Basin, Ethiopia. J. Hydrol. 2018, 556, 1182-1191. [CrossRef]

28. Serrat-Capdevila, A.; Valdes, J.B.; Stakhiv, E.Z. Water Management Applications for Satellite Precipitation Products: Synthesis and Recommendations. J. Am. Water Resour. Assoc. 2014, 50, 509-525. [CrossRef]

29. Maggioni, V.; Massari, C. On the performance of satellite precipitation products in riverine flood modeling: A review. J. Hydrol. 2018, 558, 214-224. [CrossRef]

30. Stisen, S.; Sandholt, I. Evaluation of remote-sensing-based rainfall products through predictive capability in hydrological runoff modelling. Hydrol. Process. 2010, 24, 879-891. [CrossRef]

31. Habib, E.; Haile, A.; Sazib, N.; Zhang, Y.; Rientjes, T. Effect of Bias Correction of Satellite-Rainfall Estimates on Runoff Simulations at the Source of the Upper Blue Nile. Remote Sens. 2014, 6, 6688-6708. [CrossRef]

32. Teutschbein, C.; Seibert, J. Bias correction of regional climate model simulations for hydrological climate-change impact studies: Review and evaluation of different methods. J. Hydrol. 2012, 456-457, 12-29. [CrossRef]

33. Chen, Y.N.; Li, Z.; Fan, Y.T.; Wang, H.J.; Fang, G.H. Research progress on the impact of climate change on water resources in the arid region of Northwest China. J. Geogr. Sci. 2014, 69, 1295-1304. (In Chinese)

34. Wang, S.; Ding, Y.; Iqbal, M. Defining Runoff Indices and Analyzing Their Relationships with Associated Precipitation and Temperature Indices for Upper River Basins in the Northwest Arid Region of China. Water 2017, 9, 618. [CrossRef]

35. Chen, Y.; Li, Z.; Fan, Y.; Wang, H.; Deng, H. Progress and prospects of climate change impacts on hydrology in the arid region of northwest China. Environ. Res. 2015, 139, 11-19. [CrossRef] [PubMed]

36. Wang, P.; Yu, J.; Zhang, Y.; Liu, C. Groundwater recharge and hydrogeochemical evolution in the Ejina Basin, northwest China. J. Hydrol. 2013, 476, 72-86. [CrossRef]

37. Chen, Y.; Deng, H.; Li, B.; Li, Z.; Xu, C. Abrupt change of temperature and precipitation extremes in the arid region of Northwest China. Quat. Int. 2014, 336, 35-43. [CrossRef]

38. Su, Y.Z.; Zhao, W.Z.; Su, P.X.; Zhang, Z.H.; Wang, T.; Ram, R. Ecological effects of desertification control and desertified land reclamation in an oasis-desert ecotone in an arid region: A case study in Hexi Corridor, northwest China. Ecol. Eng. 2007, 29, 117-124. [CrossRef]

39. Sapiano, M.R.P.; Arkin, P.A. An Intercomparison and Validation of High-Resolution Satellite Precipitation Estimates with 3-Hourly Gauge Data. J. Hydrometeorol. 2009, 10, 149-166. [CrossRef]

40. Gao, Y.C.; Liu, M.F. Evaluation of high-resolution satellite precipitation products using rain gauge observations over the Tibetan Plateau. Hydrol. Earth Syst. Sci. 2013, 17, 837-849. [CrossRef]

41. Wang, N.A.; Zhang, J.M.; Cheng, H.Y.; Guo, J.Y.; Zhao, Q. The age of formation of the mirabilite and sand wedges in the Hexi Corridor and their paleoclimatic interpretation. Chin. Sci. Bull. 2003, 48, 1439-1445. [CrossRef]

42. Feng, Q.; Li, Z.; Liu, W.; Li, J.; Guo, X.; Wang, T. Relationship between large scale atmospheric circulation, temperature and precipitation in the Extensive Hexi region, China, 1960-2011. Quat. Int. 2016, 392, 187-196. [CrossRef]

43. Ding, H.; Zhang, J. Relationships between sustainable development and water resources in arid oases area-An example of HEXI corridor. J. Arid Land Resour. Environ. 2004, 18, 50-55. (In Chinese)

44. Kang, E. Review and Prospect of Hydrological Studies in Cold and Arid Regions of China. J. Glaciol. Geocryol. 2000, 22, 178-188.

45. Tan, M.; Ibrahim, A.; Duan, Z.; Cracknell, A.; Chaplot, V. Evaluation of Six High-Resolution Satellite and Ground-Based Precipitation Products over Malaysia. Remote Sens. 2015, 7, 1504-1528. [CrossRef]

46. Huffman, G.J.; Bolvin, D.T.; Nelkin, E.J.; Wolff, D.B.; Adler, R.F.; Gu, G.; Hong, Y.; Bowman, K.P.; Stocker, E.F. The TRMM Multisatellite Precipitation Analysis (TMPA): Quasi-Global, Multiyear, Combined-Sensor Precipitation Estimates at Fine Scales. J. Hydrometeorol. 2007, 8, 38-55. [CrossRef]

47. Ebert, E.E.; Janowiak, J.E.; Kidd, C. Comparison of Near-Real-Time Precipitation Estimates from Satellite Observations and Numerical Models. Bull. Am. Meteorol. Soc. 2007, 88, 47-64. [CrossRef] 
48. Arias-Hidalgo, M.; Bhattacharya, B.; Mynett, A.E.; van Griensven, A. Experiences in using the TMPA-3B42R satellite data to complement rain gauge measurements in the Ecuadorian coastal foothills. Hydrol. Earth Syst. Sci. 2013, 17, 2905-2915. [CrossRef]

49. Vernimmen, R.R.E.; Hooijer, A.; Mamenun; Aldrian, E.; van Dijk, A.I.J.M. Evaluation and bias correction of satellite rainfall data for drought monitoring in Indonesia. Hydrol. Earth Syst. Sci. 2012, 16, 133-146. [CrossRef]

50. Anjum, M.N.; Ding, Y.; Shangguan, D.; Tahir, A.A.; Iqbal, M.; Adnan, M. Comparison of two successive versions 6 and 7 of TMPA satellite precipitation products with rain gauge data over Swat Watershed, Hindukush Mountains, Pakistan. Atmos. Sci. Lett. 2016, 17, 270-279. [CrossRef]

51. Yuan, F.; Zhang, L.; Win, K.; Ren, L.; Zhao, C.; Zhu, Y.; Jiang, S.; Liu, Y. Assessment of GPM and TRMM Multi-Satellite Precipitation Products in Streamflow Simulations in a Data-Sparse Mountainous Watershed in Myanmar. Remote Sens. 2017, 9, 302. [CrossRef]

52. Li, D.; Christakos, G.; Ding, X.; Wu, J. Adequacy of TRMM satellite rainfall data in driving the SWAT modeling of Tiaoxi catchment (Taihu lake basin, China). J. Hydrol. 2018, 556, 1139-1152. [CrossRef]

53. Joyce, R.; Arkin, P.A. Improved Estimates of Tropical and Subtropical Precipitation Using the GOES Precipitation Index. J. Atmos. Ocean. Technol. 1997, 14, 997-1011. [CrossRef]

54. Ferraro, R.R.; Smith, E.A.; Berg, W.; Huffman, G.J. A Screening Methodology for Passive Microwave Precipitation Retrieval Algorithms. J. Atmos. Sci. 1998, 55, 1583-1600. [CrossRef]

55. Scheel, M.L.M.; Rohrer, M.; Huggel, C.; Santos Villar, D.; Silvestre, E.; Huffman, G.J. Evaluation of TRMM Multi-satellite Precipitation Analysis (TMPA) performance in the Central Andes region and its dependency on spatial and temporal resolution. Hydrol. Earth Syst. Sci. 2011, 15, 2649-2663. [CrossRef]

56. Chen, S.; Hong, Y.; Gourley, J.J.; Huffman, G.J.; Tian, Y.; Cao, Q.; Yong, B.; Kirstetter, P.; Hu, J.; Hardy, J.; et al. Evaluation of the successive V6 and V7 TRMM multisatellite precipitation analysis over the Continental United States. Water Resour. Res. 2013, 49, 8174-8186. [CrossRef]

57. Yong, B.; Hong, Y.; Ren, L.; Gourley, J.J.; Huffman, G.J.; Chen, X.; Wang, W.; Khan, S.I. Assessment of evolving TRMM-based multisatellite real-time precipitation estimation methods and their impacts on hydrologic prediction in a high latitude basin. J. Geophys. Res. Atmos. 2012, 117, D09108. [CrossRef]

58. Tan, M.; Duan, Z. Assessment of GPM and TRMM Precipitation Products over Singapore. Remote Sens. 2017, 9, 720. [CrossRef]

59. Ali, A.; Xiao, C.; Anjum, M.; Adnan, M.; Nawaz, Z.; Ijaz, M.; Sajid, M.; Farid, H. Evaluation and Comparison of TRMM Multi-Satellite Precipitation Products with Reference to Rain Gauge Observations in Hunza River Basin, Karakoram Range, Northern Pakistan. Sustainability 2017, 9, 1954. [CrossRef]

60. Chen, S.; Hong, Y.; Cao, Q.; Gourley, J.J.; Kirstetter, P.; Yong, B.; Tian, Y.; Zhang, Z.; Shen, Y.; Hu, J.; et al. Similarity and difference of the two successive V6 and V7 TRMM multisatellite precipitation analysis performance over China. J. Geophys. Res. Atmos. 2013, 118, 13060-13074. [CrossRef]

61. Zhao, T.; Yatagai, A. Evaluation of TRMM 3B42 product using a new gauge-based analysis of daily precipitation over China. Int. J. Climatol. 2014, 34, 2749-2762. [CrossRef]

62. Wolff, D.B.; Marks, D.A.; Amitai, E.; Silberstein, D.S.; Fisher, B.L.; Tokay, A.; Wang, J.; Pippitt, J.L. Ground Validation for the Tropical Rainfall Measuring Mission (TRMM). J. Atmos. Ocean. Technol. 2005, 22, 365-380. [CrossRef]

63. Pipunic, R.C.; Ryu, D.; Costelloe, J.F.; Su, C. An evaluation and regional error modeling methodology for near-real-time satellite rainfall data over Australia. J. Geophys. Res. Atmos. 2015, 120, 10767-10783. [CrossRef]

64. Xue, X.; Hong, Y.; Limaye, A.S.; Gourley, J.J.; Huffman, G.J.; Khan, S.I.; Dorji, C.; Chen, S. Statistical and hydrological evaluation of TRMM-based Multi-satellite Precipitation Analysis over the Wangchu Basin of Bhutan: Are the latest satellite precipitation products 3B42V7 ready for use in ungauged basins? J. Hydrol. 2013, 499, 91-99. [CrossRef]

65. Liu, J.; Duan, Z.; Jiang, J.; Zhu, A. Evaluation of Three Satellite Precipitation Products TRMM 3B42, CMORPH, and PERSIANN over a Subtropical Watershed in China. Adv. Meteorol. 2015, 2015, 151239. [CrossRef]

(C) 2018 by the authors. Licensee MDPI, Basel, Switzerland. This article is an open access article distributed under the terms and conditions of the Creative Commons Attribution (CC BY) license (http:/ / creativecommons.org/licenses/by/4.0/). 